\title{
Eudaimonism about Virtue and Qualified Agent Right Action: Some Prospects for Environmental Virtue Ethics
}

\author{
by
}

Duncan Christian Martin

\begin{abstract}
A thesis
submitted to Victoria University of Wellington

in fulfilment of the requirements for the degree of

Master of Arts in Philosophy
\end{abstract}

Victoria University of Wellington

June 2014 


\section{Acknowledgements}

I would like to thank everyone in the Victoria University of Wellington Philosophy department. In particular, thanks to my supervisor Ramon Das for his guidance, encouragement and feedback on this thesis. Thanks also to Mum \& Dad, and to the rest of my family \& friends. 


\begin{abstract}
In this thesis, I aim to show that virtue oriented approaches to environmental ethics are in a position to provide satisfying answers to two central ethical questions: "What kind of person should I be?", and "What should I do?” I argue that two such approaches - Rosalind Hursthouse's environmental virtue ethics and Philip Cafaro's account of environmental vice - provide insights about how we ought to be with regard to the environment, in terms of character and attitudes. I then defend Hursthouse's account of right action against several objections. First, I respond to the worry that a shortage of environmental exemplars might count against Hursthouse, by showing that non-virtuous agents can conceive of what to do by seeking to avoid acting from environmental vices. Second, I respond the worry that her account of right action fails to generate the right result for non-virtuous agents in some cases, by showing that such cases can be accounted for by appeal to the distinction between action guidance and action assessment. Third, I consider the worry that her theory will fail to provide concrete action guidance. Theories which seek to provide concrete action guidance in all contexts face serious problems of their own, I respond. Further, I maintain that Hursthouse is not ruled out from providing the sort of action guidance her critics are interested in.
\end{abstract}




\section{Contents}

Acknowledgements 2

Abstract 3

Contents $\quad 4$

Introduction $\quad 6$

1. Environmental Virtues and Vices 9

1.1. Introduction 9

1.2. Norms of Character 10

$\begin{array}{ll}\text { 1.2.1. The Green Belief } & 10\end{array}$

1.2.2. Applying Environmental Virtues and Vices $\quad 11$

1.3. What Makes a Character Trait a Virtue? $\quad 15$

1.3.1. Locating Character in a Theory of Right Action $\quad 15$

1.3.2. Eudaimonism about What Makes a Character Trait a Virtue 18

1.3.3. Objections to Eudaimonism 20

1.3.4. A Response to Sandler 21

1.4. Conclusion $\quad 23$

2. Environmental Exemplars and Epistemological Problems 25

2.1. Introduction $\quad 25$

2.2. Common Objections to Virtue Ethical Right Action 26

2.3. Exemplars of Environmental Virtue $\quad 28$

2.3.1. An Epistemological Challenge to Environmental Virtue Ethics 28

2.3.2. A Possible Response: Exemplarism 30

2.3.3. V-Rules and Environmental Vices: Another Possible Response 33

2.4. Conclusion 34

3. Non-Virtuous Agents and the Qualified Agent Principle of Right Action $\quad 36$

3.1. Introduction 36

3.2. Non-Virtuous Agents and Self-Improvement: An Objection from Johnson $\quad 38$

3.2.1. Three Counter-Examples 38

3.2.2. Action Guidance and Action Assessment: A Response to Johnson 39

3.3. 'Right Actions' and 'Right Moral Decisions': Addressing Svensson 42 
3.4. Distinctively Virtue Ethical Right Action and Eudaimonia:

Addressing Das

3.5. Contextual Factors and Conflicting Action Guidance:

Addressing Sandler

3.6. Conclusion

4. Action Guidance and Environmental Virtue Ethics

4.1. Introduction

4.2. Can Virtue Ethics Provide Concrete Action Guidance?

4.2.1. Three Objections from Louden

4.2.2. Environmental Heroes and Concrete Acts: A Response from Frasz 55

4.2.3. A Response on Behalf of Hursthouse 57

4.2.4. Is Concrete Action Guidance Desirable? A Response from Annas 58

4.3. Can Environmental Virtue Ethics Provide Concrete Action Guidance? 61

4.3.1. One Possible Solution: Environmental Vices and 'Obvious' Prohibitions 61

4.3.2. Objections to All Virtue Oriented Approaches to Environmental Ethics 63

4.3.3. Should Environmental Virtue Ethics provide a Decision Procedure? 64

4.3.4. Hursthouse and Concrete Action Guidance: Some Prospects 65

4.4. Conclusion $\quad 70$

5. Conclusion $\quad 71$

$\begin{array}{ll}\text { Bibliography } & 73\end{array}$ 


\section{Introduction}

A principle of right action functions within a virtue-oriented ethical theory in the same way that a principle of right action functions within consequentialism and deontology. The theory's principle of right action is filled out by providing an account of the virtuous agent, or substantive accounts of the virtues, in the same way a value axiology does so in a consequentialist theory, and in the same way that an account of the moral law does so in a deontological theory (Hursthouse, 1999; Sandler, 2007).

In a theory of environmental ethics, the aim is to provide an account of the norms of character and the norms of action which ought to govern our human relationship with the natural environment. If the two central ethical questions are "What kind of person should I be?" and "What should I do?”, a theory of environmental virtue ethics needs to provide a satisfying answer to both, informing us on the qualities of character we ought to cultivate with regard to the environment, and the sorts of behaviour we ought to engage in with regard to the environment (Sandler, 2005: p.2).

These two rather broad characterizations provide a useful framework for understanding the project of constructing a virtue-oriented approach to environmental ethics, along with the potential obstacles facing such a project. Of particular importance, it is expected that a theory of this kind meets a common objection to virtue ethics - the charge that virtue ethics fails to tell us what to do. As suggested by the above characterizations of virtue ethics and environmental ethics respectively, the question of whether or not a theory can provide a plausible account of right action is not entirely divorced from the question of whether it can provide a plausible account of what makes a character trait a virtue - the latter informs the former.

In this thesis, my project is to show that virtue oriented approaches to environmental ethics are in a position to provide satisfying answers to both central ethical questions, namely, "What kind of person should I be?", and "What should I do?" with regard to the natural environment. In chapter one, I argue that two virtue-oriented approaches, namely Rosalind Hursthouse's environmental virtue ethics and Philip Cafaro's account of environmental vice, provide insights into the causes and solutions surrounding the environmental crisis, particularly in terms of character 
and attitudes. I propose a requirement that an account of the norms of character that ought to govern our relationship with the natural environment requires a background theory of virtue. I then outline Hursthouse's eudaimonistic account of what makes a character trait a virtue, defending it against a few criticisms from Ronald Sandler, and concluding that he is mistaken in asserting that we need to move to a more inclusive, pluralistic account.

In chapter two, I outline Hursthouse's theory of right action, and consider an epistemological objection to this account. The objection is that an imperfect agent cannot know what a fully virtuous agent would do in certain circumstances because they do not possess the virtues. Hursthouse responds to this objection, stating that the obvious thing for an imperfect agent to do in these circumstances is to find a virtuous agent, and ask them what they would do, should this be possible. She also claims that we come to know how to act towards the environment by conceiving of how someone who possesses the virtues would act, but also that we have very few exemplars of the relevant virtues. I interpret this latter claim as a concession, albeit an unintentional one, that her environmental virtue ethics cannot provide action guidance. I argue that this problem can be alleviated, but not by showing that imperfect agents can seek out the guidance of environmentally virtuous agents. Instead I argue that the theory provides action guidance in the form of v-rules, where each vice generates a corresponding prohibition.

As I suggested above, the spheres of interpersonal ethics and environmental ethics are not entirely divorced from one another, and in this way, problems facing virtue ethics in this first area have direct implications for the theory on the latter. In chapter three then, I consider a different family of objections against Hursthouse's principle of right action. These pertain to non-virtuous agents, where the worry is that her principle of right action fails to generate the right result for such agents, in cases where the intuitively right action is not the characteristic behaviour of a virtuous person. I respond by showing that the cases which critics of virtue ethics are concerned with here are similar to a case for which Hursthouse's distinction between action guidance and action assessment is able to account; I then try to account for them in a similar fashion.

In chapter four I consider the worry that virtue oriented approaches to environmental ethics will fail to provide concrete action guidance in specific environmental contexts. Following Julia Annas, I argue that there are compelling 
reasons to think that the goal of constructing a theory that provides concrete action guidance to any agent in any situation will likely run into serious problems of its own, in that it looks to remove an important sense in which the agent performing the act is either praiseworthy or blameworthy. Independent of this response, I argue that Hursthouse's theory is able to provide the sort of action guidance that the critics are interested in, by showing that her theory is consistent, in the relevant respects, with a theory that provides a virtue-oriented approach to environmental decision making, namely Ronald Sandler's. 


\section{Environmental Virtues and Vices}

\subsection{Introduction}

Theories of environmental ethics require both an account of the norms of action, and an account of the norms of character that ought to govern our interactions with nature (Sandler, 2005: p.2). This chapter is concerned with the project of outlining the latter, in relation to virtue oriented approaches to the theory, and discussing what Rosalind Hursthouse describes as "the green belief", a view, common to environmental ethicists, that a fairly radical shift in the way we engage with nature is vital (2007: p.155).

My first goal is to outline what I take to be the key themes running through virtue oriented approaches to environmental ethics and elaborate on the ways in which approaches of this kind account for the human relationship with the environment, particularly in regard to the qualities of character we ought to cultivate.

Hursthouse (2007) offers two formulations of what a theory of this kind might be like. On the first formulation, "old" virtues and vices are applied to environmental contexts, in order to gain a new understanding of what it might mean to be, for example, cruel or compassionate in such contexts. On the second formulation, she seeks to introduce two new virtues, in order to capture those areas of our relationship with the environment that "old" virtues and vices seem to be incapable of capturing (2007: p.155).

Philip Cafaro (2005) is concerned with the idea that our professed values about the environment are totally out of sync with our actions towards it. On his view, a great many Americans label themselves as environmentalists and strongly support policies in favour of the environment, but these same Americans, Cafaro thinks, behave in environmentally irresponsible ways. This behaviour, according to Cafaro, stems from certain character defects - environmental vices - namely gluttony, arrogance, greed and apathy (Cafaro, 2005: p. 135).

Throughout the early part of this chapter I will discuss the ways in which virtueoriented approaches can provide insights into the causes and solutions surrounding the environmental crisis, particularly in terms of character and attitudes, making use of the two accounts considered above.

Sandler argues that we must provide a background theory of what makes a character trait a virtue, to ensure that the normative claims we make are more than mere 
rhetoric (2007: p.2).

On this score I will outline and defend Hursthouse's general eudaimonistic account of what makes a character trait a virtue, showing the place that such an account occupies in her theory of right action. In doing so, I will consider Sandler's criticisms of this account, which prompt him to construct a teleological, pluralistic, naturalistic account of what makes a character trait a virtue.

I contend that the criticisms given by Sandler on this point are not decisive, mainly because they rest upon an unsubstantiated claim about whether any purportedly non-eudaimonistic ends come into play, when considering the question of what makes a character trait a virtue.

\subsection{Norms of Character}

\subsubsection{The Green Belief}

It is apparent that the environmental crisis facing the world today is, at least partially, a product of our relationship as humans with non-human nature. Climate change sceptics aside, it is commonly acknowledged that global warming, rising sea levels, ozone layer depletion, and deforestation are among the many environmental issues we ought to concern ourselves with. Several factors have played a role in creating these problems: rapid population growth, worldwide technological developments that have enabled an increase in the human use of resources, and free market economies that place economic factors at the centre of decision making around issues such as waste treatment. Above all, it could be said that both the causes and solutions lie in our beliefs, attitudes and values towards nature. Attitudes that regard the natural environment as something freely available to us, and something to which we can do whatever we like, are particularly prevalent in western societies (Park, 2007: p.151). It may be argued that a fairly radical shift in the way in which we engage with nature is vitally important. This particular line of thought, described by Rosalind Hursthouse as "the green belief", is very much the focus of environmental ethics, a field that sets out to understand the human relationship with nature, and determine the norms that ought to govern our interactions with it (Hursthouse, 2007; Sandler, 2005: p.1).

The claim that we ought to bring about a radical shift carries with it the suggestion that there is something wrong with the way we currently engage with nature, a claim 
that needs to be demonstrated with reference to some account of rightness. To go about demonstrating the wrongness of the human relationship with nature, theories of environmental ethics require both an account of the norms of action, and the norms of character that ought to govern our interactions with it. Ronald Sandler describes environmental virtue ethics as the project of identifying the latter, a claim that carries with it the suggestion that the theory can remain agnostic on the role of identifying the former (i.e. that it can play a supplementary role to non-virtue ethical versions of environmental ethics). In Sandler's view, the central ethical question is "How should one live?" He believes that a full treatment of that question will inform not only what we ought to do, but also the kind of person we ought to be, in terms of what attitudes and dispositions we ought to have (2005: p.1-2). In my view, and as Sandler argues elsewhere (2007), virtue ethics, despite its emphasis on the latter, can provide a plausible account of right action, a proposal that I will discuss in later chapters.

\subsubsection{Applying Environmental Virtues and Vices}

For the purposes of this chapter then, let us consider what the theory brings to the table in regard to the norms of character an environmental ethics would require, along with the general question: "What is it that is so wrong with the way we engage with nature?" Hursthouse (2007) offers two such answers. On the one hand, we can go about defending the green belief in terms of "old" virtues and vices - those on the standard list. The strategy involved here is to pick out the virtue or vice relevant to our relations with nature, to discuss it in this context, and to thereby give it a new application or dimension, in order to gain a new perception, or understanding of what it means to possess that character trait - i.e, to be arrogant or properly humble, cruel or compassionate with regard to the environment, and so forth. In virtue ethical terms then, one possible way of demonstrating the wrongness of the way in which we engage with nature, is to reconfigure these virtues and vices as follows. Perhaps it is the case that present ecological disasters we face have been brought about by the vices of greed, in owning several cars, and short-sightedness, in failing to consider future generations. What we lack is the virtue of prudence, the decision procedure which enables thoughtful action - the cultivation, and possession of which would provide the means to solve these issues, along with the more specific virtues that prudence enables us to possess (Hursthouse, 2007: p.155). 
In addition to this, Hursthouse suggests another strategy. It may be that those "old" virtues and vices standardly thought to have a direct application to environmental issues, particularly proper humility and arrogance, do not seem to capture everything we would expect to see involved in one's proper relationship with nature, and one's attitude towards it. On such grounds, Hursthouse proposes a second version of environmental virtue ethics, which involves the introduction of two new virtues, the first being a disposition to feel the emotion of wonder in the right way (explicitly in terms of the wonders of nature, perhaps), and the second being a respect for nature, or as she prefers to call it, the disposition to be rightly oriented toward nature (Hursthouse, 2007: p. 161-167). As I understand her second version of the theory, the wrongness of our behaviour toward the environment then looks to manifest itself in the fact that a great many of us fail to possess, and act from, these nature-specific virtues.

In any case, if a radical shift in the way we engage with nature is imperative, then surely, just who counts as the "we" in this equation will quite likely be a matter of degree, particularly in terms of accountability. I do not personally go about dumping toxic waste into the streams, or contaminating waterways with agricultural effluent runoff, and nor do I advocate policies that allow practices of this kind to occur. However, assuming that practices of this kind do occur, the prices I pay for car batteries and milk are presumably lower than they would be if companies took on more environmentally-friendly practices, so there is no doubt that I benefit from those harms in that sense. Similarly, whether directly, by the places we travel, or causally, through the products we buy, as consumers we collectively rely on transport methods that contribute heavily to environmental degradation, particularly ozone layer depletion. Like any other ordinary western citizen then, I am not absolved from the harms caused to the environment, even if, for instance, my carbon footprint is considerably less than that of major culprits.

These points are recognized by both Hursthouse and Philip Cafaro in their respective versions of environmental virtue ethics. That there is a matter of degree across individuals in the wrongness of the way they engage with nature can be expressed, on Hursthouse's view, by the idea that one's wrong behaviour can be interpreted as either expressive of a vice, or to a lesser degree reflective of that agent's failure to possess or act upon the corresponding virtue. On the application of "old" virtues and vices to the examples of animal suffering and human slavery, she writes: 
The fact that I myself, as an ordinary deskbound city-dweller, am not actually out and about inflicting cruelty on chickens, sheep, cows, pigs and so on, may preserve me from rightly being called 'cruel' but I do not merit being called compassionate, if, knowing about the cruel practices, I still enjoy their fruits, any more than I merit being called just if I knowingly enjoy the fruits of slave labour while congratulating myself on not actually being a slave owner (Hursthouse, 2007: p.156).

In relation to the earlier example, a similar application can be made. In pointing to the fact that I do not pollute land and streams, and the fact that I keep my carbon footprint as low as I possibly can while still owning a car, I should rightly be able to avoid being described as arrogant, or apathetic in my exchanges with the environment (or whatever the relevant environmental vices may be). At the very same time, by enjoying the fruits of these ecological harms, knowingly (presuming the causal connection I described is not merely hypothetical), and by continuing to willingly use environmentally harmful transport methods, sometimes, I cannot correctly call myself 'rightly oriented to nature' (or whatever the relevant environmental virtue may be). In any case, there is certainly a matter of degree here - I am probably not as accountable as someone who pollutes the environment, but am clearly still well short of possessing the relevant environmental virtues to any high degree.

In some ways then, it may be correct to describe our behaviour toward the environment as falling somewhat short of virtue, rather than expressive of vice, but in others, a less sympathetic analysis may be in order. Cafaro (2005) is concerned with the idea that our professed values about the environment are totally out of sync with our actions towards it. As he has it, a great majority of Americans see themselves as environmentalists, and strongly support policies in its favour, but that same majority behave in environmentally irresponsible ways. In relation to the points made earlier, it is largely inescapable that we rely on environmentally harmful transport methods and products, (short of moving off the grid, or starting a commune, say) but in any case, the extent to which we do so is not. On Cafaro's view, it is granted that the major causes of the crisis at hand are structural and political, though it is clear that all of us, or at least all of us that care for nature, share some responsibility to make wiser environmental decisions in our everyday lives. As he points out, even within our urbanized, western lives, there is genuine choice in a lot 
of cases - "nobody forces us to buy big SUVs, build three-car garages or let our bicycles rust" (2005: p.135-136). His explanation for the gap between our professed values, and our real actions, is that our poor behaviour stems from particular character defects or vices (Cafaro, 2005: p.135-136).

It is important to consider a further question. In what ways can a virtue-oriented approach to environmental ethics add weight to the claim that our attitudes toward nature are both a leading cause of the crisis at hand, and a major obstacle to providing viable solutions? Earlier, I suggested that the causes and solutions to the environmental crisis lay in our attitudes toward nature. I am convinced that attitudes which view nature as something to which we can do whatever we like, as well as attitudes that reflect failings in our own lives generally are (at least partially) the cause of the environmental crisis, insofar as they motivate bad behaviour toward the environment - such as the wanton destruction of trees, the careless pollution of rivers, and so forth. This much is consistent with Cafaro's views about the environment-specific vices. It is easy to see the environmental harms of gluttony, for instance, the vice that refers to excessive overindulgence in eating and drinking. A study in 2000 by the U.S. Department of Agriculture's Economic Research Unit uncovered that Americans consumed 2800 calories per day on average, 600 calories higher than necessary. This habit of consuming approximately $25 \%$ more than the recommended intake meant that the amount of land needed to graze animals and grow crops also grew by $25 \%$, leading to further increases in the amount of pollutants dumped on the land, and running into rivers and streams by 25\% (Cafaro, 2005: p.141).

Following this general line, if we are to go about solving the environmental crisis, our attitudes toward nature are in much need of replacement, insofar as we need to motivate good behaviour toward the environment. A virtue-oriented approach would say that good behaviour comes from the right orientation toward nature, insofar as the environmentally virtuous agent is disposed to respond to the environment in an excellent or fine way, both emotionally, and through action (Sandler, 2005: p.3). On account of the "old" virtues and vices then, and in relation to Cafaro's example, one can discuss temperance as being environmentally relevant one who possesses and cultivates the character trait of temperance correctly assigns due weight to one's pleasures, and they do so for the right reasons, remaining happily on a diet of 2200 calories, and thereby contributing to a more environmentally 
sustainable level of agricultural production and the like. As an attitude, temperance, by itself, will not solve the environmental crisis - human beings will need a fair amount of work on cultivating other environmental virtues - but it certainly goes a long way to cancelling out gluttony. If my analysis is correct, it follows that virtueoriented approaches look to identify the norms of character that ought to govern our relationship with the natural environment. The specification of environmental virtue and vice allows us to demonstrate the wrongness of our present human relationship with nature in terms of character and provides insights into how our attitudes towards the environment may be in need of revision, in light of present ecological disasters.

\subsection{What Makes a Character Trait a Virtue?}

\subsubsection{Locating Character in a Theory of Right Action}

Thus far I have been operating with Sandler's assumption that an adequate environmental ethic is required to provide an account of the norms of action and norms of character which ought to govern our human behaviour with the natural environment (2005: p.2). It is worth considering a few potential obstacles for virtue oriented approaches, when confronted with the task of specifying the latter, in particular, around whether it provides the resources to meet the requirements of an adequate environmental ethic. In Character and Environment (2007), Sandler writes that an environmental ethic is adequate to the extent that it:

A: Provides a basis for reliable, sustained, and justified critique of environmentally unsustainable practices, policies and lifestyles.

B: Provides action and policy guidance in concrete situations involving individual or community interactions or relationships with the natural environment.

C: Provides arguments, reasons, or justifications that are efficacious in moving people to perform the actions or adopt the policies that are recommended (2007: p.108).

I should make it clear that condition A is the primary focus of my discussions in this chapter. In chapter four, I use condition B as a general framework for my discussions on Hursthouse's arguments in relation to the worry that a virtue oriented approach to environmental ethics will fail to provide concrete action guidance in 
specific environmental contexts. In both cases, however, I will remain agnostic on whether condition $\mathrm{C}$ can be met.

Since the focus of this chapter is on specifying the norms of character that ought to govern our relationship with the natural environment, let us consider the relevance of the question "what makes a character trait a virtue?" in relation to virtue-oriented approaches to environmental ethics. According to Sandler, if we want our claims about which character traits are environmental virtues and vices to be more than rhetoric, we must give a basis or standard for their evaluation. Further, he thinks that disagreements about which character traits are environmental virtues and vices often stem from different accounts of what makes a character trait a virtue or vice in general (Sandler, 2007: p.9).

It can be reasonably assumed then, that the task of forming an account of what makes a character trait an environmental virtue is central to whether or not a virtue oriented approach to environmental ethics can provide the resources to meet condition A. My arguments in the early part of this chapter were an attempt to defend the green belief, namely by providing an explanation for why our current relationship with the natural environment is problematic. If such arguments are sound, environmental virtue ethics provides seems to provide a basis of critique for environmentally unsustainable lifestyles, policies and practices. However, even if the claims made in that section are compelling, for instance, on temperance as an environmental virtue, it might be argued that they lack normative force, in the absence of a general theory about what makes a character trait a virtue.

The task for the remainder of this chapter will be to overcome this issue, by defending Hursthouse's eudaimonistic account of what makes a character trait a virtue, showing that the general account underwrites both of her proposed versions of environmental virtue ethics.

Sandler thinks that there are serious difficulties for a certain type of approach to specifying environmental virtue, which he describes as the environmental exemplar approach. Approaches of this kind begin from a prior conception of which agents are environmentally virtuous, which is problematic, in the sense that they fail to provide the means to adjudicate between conflicting views about who is environmentally virtuous. As Sandler has it, this does not diminish the importance of the study of moral exemplars. However, a background theory of what makes a character trait a virtue or vice is necessary for avoiding such issues, while allowing us to more 
accurately track what makes a character trait an environmental virtue (Sandler, 2007: p.13).

In any case, there is a further need to provide such an account of what makes a character trait a virtue. A principle of right action functions within a virtue-oriented ethical theory in the same way that principles of right action function with consequentialism and deontology (Hursthouse, 1999; Sandler, 2007). For example, the principle of right action governing many act-consequentialist theories is "An action is right if and only if it promotes the best (or good enough) consequences", whereas the principle governing many deontological theories is "An action is right if and only if it conforms to the moral law" (Sandler, 2007: p.86). Each principle is provided with content or made more substantive by an account of the best consequences (e.g. the satisfaction of peoples' desires or the maximization of pleasure), and an account of the moral law (e.g. rules that are commanded by God or maxims that are universalizable) respectively (Sandler, 2007: p.86).

The principles of right action governing virtue-oriented ethical theories are filled out by providing an account of the virtuous agent, or substantive accounts of the virtues. In either case, the virtues are providing content to the virtue oriented principle of right action, just as a value axiology provides content to consequentialist principles of right action, and an account of the moral law provides content to deontological principles of right action. As much of my focus throughout this thesis will be on showing how Hursthouse's virtue ethics can meet objections against its principle of right action, let us locate that principle of right action in relation to her virtue ethical theory as a whole, in order to show the place that a eudaimonistic account of virtue occupies within it:

P.1. An action is right iff it is what a virtuous agent would characteristically (i.e. acting in character) do in the circumstances

P.1a. A virtuous agent is one who has, and exercises, certain character traits, namely, the virtues

P.2. A virtue is a character trait that is needed by human beings for eudaimonia, to flourish or live well (Hursthouse, 1999: p.28-29) By introducing the concept of the virtuous agent, the principle itself implicitly introduces the idea that a virtuous agent possesses the virtues, which implicitly introduces the idea that a virtue is a character trait that a human being needs for flourishing, or eudaimonia. (Hurshouse, 1999: p.29). In this way, what makes an 
action right is defined, in part, by what makes a character trait a virtue.

\subsubsection{Eudaimonism about What Makes a Character Trait a Virtue}

In basic terms then, Hursthouse's eudaimonistic account of what makes a character trait a virtue is that "virtues are character traits that a person needs to flourish or live well" (Sandler, 2007: p.14). To provide content to that view, Hursthouse commits herself to a few further claims. First, she argues that claims about "good" human beings are analogous, in terms of evaluative structure, to claims about "good" individuals of other species and life forms. The sense in which the term "good" is being used here is crucial in showing how the two are analogous. As Hursthouse points out, "Good", belongs to a class of attributive adjectives which includes terms like "large" and "small" (1999: p.195).

Further, and consistent with Hursthouse's view, Philippa Foot notes that "good" as an attributive adjective, has different properties to predicative adjectives, like the word "red". The word "red" operates independently of any noun to which it is attached. When the term "good" is attached to a noun, however, for example, in the sentence "a good F", whether or not a particular F counts as a good F depends heavily on what is substituted for the term "F". If one realizes that one has discovered a mouse, after mistakenly thinking it was a rat, one's description of that animal changes from "large" to "small". In the same way, "bad" might change to "good" when we consider a work of philosophy first as a work of philosophy, then as a soporific. Questions around whether or not a particular thing is good cannot be answered without thinking of it as a member of a certain kind. In order to understand what makes a particular $\mathrm{F}$ a good $\mathrm{F}$, first we must come to understand the nature of Fs (Foot, 2001: p.2-3).

In line with this reasoning, Hursthouse's general account entails that there should not be a surprising transformation in the structure of evaluative judgements of goodness and badness, when we move first from assessments of plants to assessments of nonhuman animals, and further, to assessments of human beings. This form of evaluation can be applied to human beings, and it can be done so not only with regard to biological evaluations (i.e. assessments of health), but further, with respect to character evaluations (i.e. assessments of virtue and vice). Assessments of virtue and vice involve evaluating what is left after we have separated out the bare biological parts and processes, namely, emotions, desires, and actions 
(from both reason and inclination) (Sandler, 2007: p.17). In this way, Hursthouse provides the following framework for assessing human beings:

A human being is ethically good (i.e. virtuous) insofar as she is well fitted with respect to her (i) emotions, (ii) desires, and (iii) actions (from reason and inclination); whether she is well fitted is determined by whether these aspects well serve (1) her survival, (2) the continuance of the species, (3) her characteristic freedom from pain and characteristic enjoyment, and (4) the good functioning of her social groups - in the way characteristic of human beings, (Hursthouse, 1999: p.202).

On her view then, for one to be a good human being, it is necessary that one is well endowed with regard to the aspects listed. To possess human virtues is to be well endowed in this way. According to Hursthouse, the human virtues make their possessor good qua human being (1999: p.208). A person who possesses human virtues is "good" in the sense that she is a good member of a certain kind. In light of Foot's claim that I pointed out earlier, we cannot know what it means for a particular F to be a good F, until we come to understand the nature of Fs. Hursthouse's account, in this way, provides us with a framework for understanding the nature of Fs, so to speak. It provides us with a framework for understanding the nature of human beings, so that we can assess whether or not a certain human being is a "good" human being. Whether or not a human being is a good human being turns upon whether or not she is well fitted with regard to her emotions, desires and actions. Whether or not she is well fitted with regards to her emotions, desires and actions turns upon whether these aspects serve her ability to live well and flourish. In this way then, a virtue is a character trait a human needs in order to flourish - it is a character trait they need to realize those four eudaimonistic ends - in a characteristically human way (Hursthouse, 1999: p.208).

It is worth pointing out that this general eudaimonistic account is consistent with the two respective versions of environmental virtue ethics proposed by Hursthouse. In short, it is clear that the eudaimonistic account underwrites each version, and thus, each account of what makes a character trait an environmental virtue. On the first version, we take an "old” virtue or vice, and gain a new perception or understanding of what it means to act in accordance with that virtue or vice, in an environmental context. Thus, it is assumed from the outset that the "old" virtue or vice in question has gained its status as a result of the naturalistic framework considered - an "old" 
virtue is a character trait that is needed by a human being for eudaimonia, to flourish or live well. On the second version, which seeks to introduce new virtues, the stringent framework Hursthouse considers for the introduction - or discovery - of a virtue is consistent with the naturalistic framework above, emphasizing the fact that possession of a virtue is concerned with certain dispositions and emotional reactions (2007: p. 158, 160).

\subsubsection{Objections to Eudaimonism}

Returning to the question of what makes a character trait a virtue in general, let us consider a few objections to Hursthouse's account from Ronald Sandler. First, Sandler questions the eudaimonistic assumption underpinning the arguments made by Hursthouse, in her account of what makes a character trait a virtue. According to eudaimonism, he writes, ethics is about flourishing or living well, and a person is virtuous or ethically successful if she is well disposed to do so. However, if the central ethical question is "How should I live?" then the fundamental ethical question concerning character is "What kind of person should I be?" according to Sandler. This question has broader scope than the question "What character traits are conducive to my flourishing?” Furthermore, on Sandler's view our rational and psychological capacities allow us to value things in their own right, and acknowledge that such value makes a claim upon us to respond to them, irrespective of whether being disposed to do so promotes our own flourishing, or is constitutive of it. On these grounds, according to Sandler, even if eudaimonistic considerations turn out to be the only relevant considerations when we come to assess character traits, it is presumptuous to rule out the possibility that other types of reason-giving considerations will arise, from the beginning (Sandler, 2007: p.27).

It is a possibility that what makes a character trait a virtue is not a single feature, (such as the promotion of good states of affairs or benefitting the agent), but several, according to Sandler. The bare possibility that this might be so prompts him to move to a more inclusive or pluralistic account of what makes a character trait a virtue, that accounts for both eudaimonistic and non-eudaimonistic ends, should there be any (Sandler, 2007: p.27).

Importantly, Sandler provides an explanation about how this possibility might be realized. If living things or sentient animals have a good of their own, a good that justifies concern for them in their own right, then certain character traits might be 
virtues, at least partly, on account of the fact that they promote, or do not hinder the realization of that good. A further possibility is the case of benevolence towards other humans. We seem to have an intuition, he thinks, that what makes this particular character trait a virtue is the promotion of someone else's good, rather than the fact that it benefits the agent who possesses that virtue, or that it enables them to flourish or live well (Sandler, 2007: p.27).

On the other hand, Sandler does not commit himself to the claim that living things and sentient animals have a good of their own, and stops short of claiming that his pluralistic account has an explanation for what the appropriate responsiveness might be for something which has the property of agent-independent value. However, he thinks that the fact that we appear to be able to recognize the possibility of such noneudaimonistic considerations, means that we must continue inquiring as to whether there are any. If it turns out there are, we need to consider whether they justify some forms of responsiveness or character traits over others (Sandler, 2007: p.27). Sandler's arguments here are strong, on account of the fact that Hursthouse's eudaimonistic account does not appear to find room for such considerations, if they should arise. Indeed, he considers one possible response from the eudaimonist. A committed eudaimonist might reply, he thinks, by arguing that she can accommodate for the sorts of considerations concerned, either by subsuming them under the four eudaimonistic ends listed in Hursthouse's account, or by including additional eudaimonistic ends. Such responses fail, he thinks, on account of the fact that they do not appreciate the nature of these additional considerations, which are distinct from eudaimonistic considerations, for the very reason that they directly concern ends and values independent of the agent's own flourishing. A eudaimonist could try arguing that noneudaimonistic ends are irrelevant to substantive specification of the virtues, but she could not expect to subsume agent-independent ends under agent-relative ends. A proposal which allows considerations unrelated to agent flourishing to justify certain character traits as virtues is not really eudaimonism, according to Sandler (2007: p.27).

\subsubsection{A Response to Sandler}

If Sandler's argument is sound, then non-eudaimonistic ends indeed seem to be a problem for Hursthouse. However, I argue that Sandler's argument against eudaimonism is not decisive in providing reason to abandon the theory as an account 
of what makes a character trait a virtue, and this is for a couple of important reasons. First, eudaimonism's supposed failure in scope rests upon unsubstantiated assumptions about the likelihood that non-eudaimonistic considerations will play a role in what makes a character trait a virtue - it is merely an open question around whether or not such considerations will play a role at all in what makes a character trait a virtue. Rather than responding by trying to explain away the importance of non-eudaimonistic considerations, or by trying subsume them under eudaimonistic ends, an obvious response is to shift the burden of proof back to Sandler on this point. As he concedes throughout his argument, the justification for abandoning the eudaimonistic account rests upon the assumption that such ends will arise - "the bare possibility" that it could be several features, rather than a single feature that makes a character trait a virtue, as he points out (Sandler, 2007: p.27). I contend that this is a trivial reason to abandon the account insofar as it rests on no further argument.

Further, there are uncertainties in his argument around what counts as a noneudaimonistic end. On a charitable interpretation of Sandler's view, one can construct a partial characterization of what might count as a non-eudaimonistic end, defining it as a reason giving consideration that is independent of an agent's flourishing (Sandler, 2007: p.27). However, no fixed parameters have been set in place as to what counts as independent of an agent's flourishing, and what does not, on his view. The absence of such parameters is problematic for Sandler, if he wants to maintain his claim that we ought to take seriously the possibility of such considerations arising. It is problematic in the sense that, if there are no parameters, there is no reason to think that any relevant reason giving consideration fails to be captured by the scope of an agent's flourishing.

In an attempt to outline the parameters for what counts as a sufficiently agentindependent consideration, Sandler could revisit his suggestion that what makes benevolence a virtue seems to be something independent of the flourishing of the agent who possesses it. He could claim, perhaps, that a sufficiently agentindependent consideration is one which is concerned with the good of others, prompting the need for a more inclusive, pluralistic account of what makes a character trait a virtue.

In line with her defense of Aristotelian Naturalism, it is likely Hursthouse would argue that we do not require an inclusive pluralistic account to justify the character 
trait of charity as a virtue, one which, like benevolence, is concerned with the good of others. The considerations justifying this character trait as a virtue, while not directly conducive to the flourishing of the agent who possesses it, are conducive to their flourishing indirectly. For example, in relation to the first eudaimonistic end the individual's survival - Hursthouse argues that charity, unlike courage, does not serve this end directly, but like a worker bee's stings, serves it indirectly. A bee's sting at first seems to not be a good part, with regard to individual survival, insofar as it promptly dies after using its sting. However, given that bees have stings, their predators come to learn to avoid bees because they sting, thereby fostering the survival of individual bees. Charity does not seem to, for the most part, foster the individual survival of its possessor. However, on account of the fact that certain members of a social group possess charity, they can often live longer as a result, avoid some suffering, and enjoy more, as a result of people helping them. Charity then, as a virtue, fosters the survival of individual humans, (while also serving the other eudaimonistic ends) indirectly (Hursthouse, 1999: p.209).

The prospect of "the good of others" counting as an agent-independent consideration is not persuasive then, on account of the fact that eudaimonists have a ready reply, namely the claim that character traits like charity and benevolence gain their status as virtues, insofar as they are indirectly conducive to an agent's flourishing. While Sandler's criticisms raise an interesting debate around the possibility of noneudaimonistic reason-giving considerations becoming relevant to our assessment of certain character traits, I argue that they do not provide sufficient reasons to reject Hursthouse's eudaimonistic account of what makes a character trait a virtue.

\subsection{Conclusion}

In sum, I have set out to show that virtue oriented approaches to environmental ethics can provide an account of the norms of character that ought to govern our relationship with the natural environment, and further, that one such approach namely Rosalind Hursthouse's approach - withstands a series of objections against its account of what makes a character trait a virtue generally. The reasoning behind such a move is as follows: a background account of what makes a character trait a virtue allows us to make normative claims that rest upon more than mere rhetoric (Sandler, 2007: p.2), and which, in doing so provide the resources for a critique of our current relationship with the natural environment. 
Further, an account of what makes a character trait a virtue functions within a virtue ethical principle of right action in the same way that an account of the best consequences functions in a consequentialist principle of right action, and an account of the moral law functions in a deontological principle of right action. As the following three chapters are concerned with objections against Hursthouse's account of right action - in both environmental and non-environmental contexts - this framework provides a useful picture of how such debates will take place. 


\section{Environmental Exemplars and Epistemological Problems}

\subsection{Introduction}

In this chapter, I will discuss Rosalind Hursthouse's virtue ethical account of right action, in light of a few commonly made objections. I focus on one such objection in more detail, an epistemological worry about the theory's main action-guiding prescription 'Do what the virtuous agent would do'. The worry is that an imperfect agent cannot know what a fully virtuous agent would do in certain circumstances because they do not possess the virtues. Hursthouse responds to this objection, stating that the obvious thing for an imperfect agent to do in these circumstances is to find a virtuous agent, and ask them what they would do, should this be possible (1999: p.35).

This objection has implications for her theory of environmental virtue ethics. If we consider the ethical question "What should I do?", with regard to the environment, Hursthouse (2007) claims that we come to know how to act with regard to the environment by conceiving of how someone who possesses the virtues would act, but also that we have very few exemplars of the relevant virtues (2007: p.168). I interpret this latter claim as a concession, albeit an unintentional one, that her environmental virtue ethics cannot provide action guidance. The worry here, in line with one raised above, is that an imperfect agent cannot know what a fully virtuous agent would do in environmental contexts, not only because they do not possess the relevant virtues, but because it is likely that there are no agents who possess the relevant virtues.

Two possible responses will be considered. First, it will be discussed whether Hursthouse can reply to this worry in the same way that she replies to the epistemological objection raised above. If a non-virtuous agent cannot determine what the right thing to do is, in some situation, she claims, they should ask a virtuous agent, should this be possible. In this fashion then, I consider the question of whether it is possible for an environmentally non-virtuous agent to seek out the advice of an environmentally virtuous agent, in order to determine the action they should perform. Drawing on Linda Zagzebski's motivation-based version of virtue ethics, along with the environmental exemplar approach outlined by Ronald 
Sandler, I consider whether Hursthouse's theory can make use of these approaches, and whether she can reply to the worry described, by providing the resources to identify environmentally virtuous agents. The conclusion I arrive at is that, while such an approach is promising, it is not clear that it will turn out to be a plausible strategy for Hursthouse, as there is a risk that her theory will not turn out to be incompatible with Zagzebski's motivation-based version of virtue ethics. Instead, I argue that Hursthouse is able to meet this challenge in another way, by showing that virtue ethics can provide imperfect agents with action guidance in environmental contexts. To determine what they ought to do, an imperfect agent can conceive of how a person who possesses environmental vice would act in the relevant circumstances, and seek to avoid such behaviour.

\subsection{Common Objections to Virtue Ethical Right Action}

An objection often made against virtue ethics (in a general sense) is the claim that, given its emphasis on "being, rather than doing", and the fact that it is "agentcentred, rather than act-centred", the theory fails to provide us with any account of what to do, or how to act. If it is the case that virtue ethics has nothing to say about right action, and thereby provides no moral guidance, it cannot be a genuine rival to consequentialism, or deontology, or so the claim goes. To address this objection, one can begin by setting out the theory as Hursthouse does:

P.1. An action is right iff it is what a virtuous agent would characteristically

(i.e. acting in character) do in the circumstances

P.1a. A virtuous agent is one who has, and exercises, certain character traits, namely, the virtues

P.2. A virtue is a character trait that is needed by human beings for eudaimonia, to flourish or live well (Hursthouse, 1999: p.28-29)

Presented in this way, Hursthouse's account provides a solid defence against common misconceptions about virtue ethics. For starters, it is not the case that the theory fails to tell us what to do - we ought to do as the virtuous agent does. The first premise by itself is open to a circularity objection. Our critic might point out that 'of course the virtuous agent "does what's right”, if she didn't, she wouldn't be virtuous; we are just going round in circles' (Hursthouse, 1999: p.30). However, according to Hursthouse, consequentialism and deontology are no different in this regard. When we are confronted with the principle "An action is right iff it produces the best 
consequences" or "An action is right iff it is in accordance with a correct moral rule or principle", it is clear that consequentialism and deontology are equally circular, insofar as they do not specify what the "best" consequences are or what the "correct" moral rule is, in their first premise. For virtue ethics, the shift to premise two, just as it does for the other theories, helps dispel the apparent circularity, by providing an account of what the theory's main concepts are.

A further action guidance objection that can be made against virtue ethics is the charge that it is impossible for an imperfect agent like me to ever know what the right thing to do is, since I do not possess the virtues (Hursthouse, 1999: p.35). Without full cultivation of the character trait of prudence, say, I cannot judge particular situations as a person of perfect practical reason would, and there is no way I could reliably judge what course of action would best serve my own interests. This cuts me off from the other-regarding virtues as well - without practical reason, I would not be able to judge which norm trumps which, in particular situations - whether it is appropriate to act from honesty at all costs, and tell the hurtful truth, or whether kindness and compassion demand that I keep quiet, for instance. It seems then that the theory tells me nothing about right action. If it is the case that one needs to be a virtuous agent in order to have knowledge of what the right thing to do would be, then virtue ethics sets the bar far too high from what we can expect from a moral theory, or so a critic may propose.

In relation to this epistemological problem, and the claim that one needs to actually be a virtuous agent to know what to do, Hursthouse offers a rather straightforward, yet adequate response. If one knows one is far from perfect, and cannot judge what a virtuous agent would do in like circumstances, the obvious way to gain the requisite knowledge is to find a virtuous agent, and ask them what they would characteristically do in particular situations, if this should be possible. As she has it, this is a far from controversial point. The seeking out of guidance from moral superiors - people we look up to, or find admirable - is a fact of moral life, one that virtue ethics straightforwardly accounts for, and one for which it is unclear how, or indeed whether rival theories can do so. In this case then, the charge that one needs to be virtuous in order to know about, and bring about right action is mistaken (1999: p.35).

As Hursthouse points out though, there is a further way that virtue ethicists can respond to the epistemological problem raised above. On her view, seeking out 
advice is not the only way in which a non-virtuous agent can apply the 'single prescription' of virtue ethics. On Hursthouse's view, we are assuming that the virtues have been enumerated as honesty, charity, fidelity, etc. and, in line with the theory's account of right action, a virtuous agent is, by hypothesis, honest, charitable, true to her word and so forth. In response to the epistemological objection then, it is simply not the case that a non-virtuous agent will have no idea what a virtuous agent would do in certain circumstances - a virtuous agent will, by hypothesis, characteristically do what is honest, charitable, true to her word and so forth, and not do what is dishonest, uncharitable, untrue to her word, and so forth. On the whole, this particular response stems from a rejection of another common objection to virtue ethics, according to Hursthouse, the claim that the theory fails to come up with any rules. On the basis of the arguments made above, it is clear that the theory provides a large number of rules, which Hursthouse describes as "v-rules". V-rules take on a similar form to action guiding principles in deontology. Each virtue generates a prescription - do what is honest, charitable, generous, and each vice generates a prohibition - do not do what is dishonest, uncharitable, or mean (1999: p.36).

\subsection{Exemplars of Environmental Virtue}

\subsubsection{An Epistemological Challenge to Environmental Virtue Ethics}

In any case, one needs to consider the force of the objections against virtue ethics' account of right action when played out on an environmental stage. Even if we grant, at least for the moment, that virtue ethics can adequately dispel charges against its account of right action in the context of interpersonal ethics, it is not clear whether the same can be said about the theory in applied cases, or rather, applied cases relating to the environment. Consider Hursthouse's claim that we can come to know what a virtuous agent would characteristically do in a particular situation (and thereby, the right thing to do) by asking them, should this be possible (1999: p.35). A defence of this kind depends on the "should this be possible" part of the equation. For one to gain knowledge and guidance about the right course of action in a particular context, it needs to be the case that the virtuous agents we look to for guidance possess the context-specific knowledge required to inform such a decision. I propose then that, if it cannot provide such answers, environmental virtue ethics is in serious danger of failing to provide a plausible account of right action. 
In "Environmental Virtue Ethics" (2007), it looks as though Hursthouse is prepared to bite the bullet on this point and concede that the theory only provides a list of fairly obvious prohibitions against "wanton, gratuitous, selfish, materialistic, and short sighted consumption, harm, destruction and despoliation" (p.167), rather than providing any reliable action guidance or answers on what we ought to do, regarding pressing problems. In response to this particular concession, she points out that it is not a problem unique to virtue-oriented approaches to environmental ethics, and that other versions provide just as little guidance for further detailed changes, going on to cite the principles identified by Paul W. Taylor, as equally obvious, namely those prohibitions against buying ivory, caging tropical birds and hunting wild rare mammals (p.168). In asking questions around whether the normative theory is incomplete, and if so, what may be missing, Hursthouse offers the following answer:

Virtue ethicists seek answers to questions about what we should do and how we should live by considering what someone who really possessed virtue to a high degree would do. And we have little idea of the answers to such questions in the context of environmental ethics, because we have so few exemplars of the relevant virtues, real or fictional, if any (Hursthouse, 2007: p.168)

I contend that this particular answer is a lot more problematic than Hursthouse suggests. It may be the case that other theories embody a similar degree of vagueness. However, if it is true that we have very few exemplars of environmental virtue, if any at all, this counts against environmental virtue ethics in a way that is both significant, and unique to the theory itself.

To put it simply, the problem is this: consider a central ethical question, namely "what should I do?" If the answer offered by environmental virtue ethics is "do what a person who possesses the virtues to a high degree would do", and if we cannot point to any such people, it appears that the theory fails to provide a satisfying answer. One might argue that the theory once again fails to tell imperfect agents "what to do". Further, it might be argued that it fails to tell us how to figure out what to do, to the extent that environmental virtue ethicists are ruled out from responding that those of us who are not environmentally virtuous can seek out the guidance of someone who is. 


\subsubsection{A Possible Response: Exemplarism}

How might Hursthouse respond to this epistemological challenge at hand? The worry, as I have stated it, is that an absence of exemplars of environmental virtue counts against Hursthouse's environmental virtue ethics. On the basis of her response to the epistemological objection raised earlier and the problems such a response faces in regard to applied ethics, one possible strategy presents itself. If I, a non-virtuous agent, cannot fathom what a virtuous agent would do in the circumstances, the appropriate thing for me to do is to find one, should this be possible, and ask them what they would do. Perhaps in an environmental context, the appropriate thing for me to do is to find an environmentally virtuous agent, and ask them what they would do, should this be possible. In this way then, if Hursthouse can provide an explanation about how to identify actual environmentally virtuous agents, out there in the world, her account of right action might remain a plausible option, in terms of providing concrete action guidance in environmental contexts.

But there remains a question around how we ought to go about identifying environmentally virtuous agents, and whether such an approach invites serious problems of its own. In some ways, the strategy I considered above mirrors a familiar approach to environmental virtue ethics identified by Ronald Sandler, one that he describes as the environmental exemplar approach for specifying environmental virtue. This approach, according to Sandler, is grounded in firm beliefs about who counts as environmentally virtuous, and "proceeds by examining the character of those exemplars to derive substantive accounts of particular environmental virtues, as well as a general account of what makes a character trait an environmental virtue" (Sandler, 2007: p.10).

According to Sandler, the environmental exemplar approach has two important limitations, resulting from the fact that it rests on beliefs about who is environmentally virtuous. First, such beliefs can be distorted, narrow or otherwise inadequate, Sandler argues, leading to mistaken assessments of some character traits, and thus, an inaccurate account of what makes a character trait an environmental virtue (Sandler, 2007: p.10).

Further, and perhaps more problematically, there are competing beliefs about who is environmentally virtuous. As Sandler notes:

The lives and characters of the heroes of North American environmentalists 
may differ substantially from those of the environmental heroes of North American sportsmen, ranchers, loggers, or developers, as well as from those of people in other parts of the world (Sandler, 2007: p.10).

A second, potentially more damaging, limitation to the environmental exemplar approach is that it does not provide the resources to adjudicate between such beliefs. If some of us, or even a lot of us deem a particular environmental figure admirable, this does not establish that the traits exemplified by such a figure are environmental virtues.

However, there are questions around whether Sandler has provided a sufficiently charitable representation of exemplarist moral theories, and whether he has prematurely dismissed the possibility of a more substantive theory, one that does not lead to distorted, narrow or otherwise inadequate beliefs about who is environmentally virtuous. One theory that is partly concerned with the identification of actual virtuous agents is Linda Zagzebski's exemplarist, motivation based version of virtue ethics. The theory is not a theory of environmental ethics per se, but it is one that potentially provides the means to identify environmentally virtuous agents. In short, Zagzebski argues that what makes an exemplar good is their motivations. We come to learn about morality by recognizing instances of good people, and imitating their motivations, often without realizing it. How we come to identify the exemplars is analogous to how we come to identify water. Most of us recognize instances of good people, just as we do water, but it takes an expert to identify the complex properties of both. Scientists can identify water as $\mathrm{H}^{2} \mathrm{O}$, through empirical discovery, and in the same way, we need to carefully observe the exemplar to find out what their properties are. Zagzebski suggests that, by rooting all the concepts of ethical theory in a person (the exemplar), narratives and descriptions of that person become a morally relevant guide for identifying the properties that make that person $\operatorname{good}(2004:$ p.46).

One suggestion then is to combine this approach with another possible strategy, wherein the lives of environmentally admirable figures are treated as narratives, that is, as morally relevant guides on how to identify the properties that make them good. If one can successfully identify the properties that make these people good, in an environmental sense, it appears that exemplarist theories of this kind would have the resources to yield detailed context-specific answers we are looking for in environmental virtue ethics, in terms of both character and action guidance, that is, 
in terms of how we ought to live, and what we ought to do.

In response to Sandler's first objection to the environmental exemplar approach sketched above, Zagzebski's theory does not afford privilege to prior beliefs about who is virtuous. Truths like " $\mathrm{H}^{2} \mathrm{O}$ is water" are discovered a posteriori, she claims, pointing out that her moral theory is constructed along similar lines, concerning how we go about discovering the properties that make a person good (2010: p.16). Further, she holds that exemplars are exemplary only for a limited range of behaviour, and even if they are not perfectly virtuous, an exemplar can fix the reference of "good", and can be successfully imitable in this regard (2004: p.56). This suggests that the identification of environmental exemplars, if undertaken in the way described, would be a potential option for environmental ethics. For Hurthouse though, it is unclear whether Zagzebski's theoretical framework is consistent with her Aristotelian version of virtue ethics. One could try to make the case that exemplarism would be a useful supplement to Hursthouse's defence of a virtue ethical account of right action. Indeed, Zagzebski's view allows for the NeoAristotelian claim that, "what makes an exemplar good is that he or she has traits that are constitutive of eudaimonia," (2004: p.49) even though the theory does not require that this be the case, which suggests that motivation based virtue ethics might be compatible with Hursthouse's Aristotelian virtue ethics.

However, recall Sandler's charge that exemplarist approaches do not have the resources to adjudicate between competing beliefs about who is environmentally virtuous. One likely response on behalf of Zagzebski is that her motivation based virtue ethics can adjudicate between such beliefs, consistent with her response to the problem of conflicting exemplars across cultures. To remedy the problem of different exemplars holding conflicting beliefs, she suggests that such exemplars can engage in sympathetic and extensive dialogue with one another, and come to fully understand the beliefs of the other that conflict with theirs. On her view, the beliefs that each exemplar adopts as the result of their encounter are virtuous (2004: p.378). Such an approach could be applied to cases where we appear to have conflicting beliefs about who is environmentally virtuous, as a means of responding to Sandler on this point. However, it is not clear this is a theoretical commitment Hursthouse would be willing to make. On this point then, I conclude that Zagzebski's motivation-based version of virtue ethics is a plausible potential option in itself, as a theory for identifying environmentally virtuous agents, one that provides compelling 
responses to the objections raised by Sandler earlier. I also conclude that it is not a plausible strategy for Hursthouse's environmental virtue ethics to undertake, as a means of identifying environmentally virtuous agents, on account of the fact that both theories are likely to turn out to be incompatible.

\subsubsection{V-Rules and Environmental Vices: Another Possible Response}

However, returning back to the issue of whether an absence of environmental exemplars counts against Hursthouse's theory of environmental virtue ethics, a different kind of response can be made. First, one could make the following point. Even if we cannot conceive of what it means to possess an environmental virtue (because eudaimonia is beyond our grasp), the theory is not inadequate. As Hursthouse argues, virtue ethics is about living well, but it is not committed to our living well being a realizable state of affairs (2007: p.170). It is simply a possibility that environmental virtue, and by extension, the acts from environmental virtue (in the sense of being actions that a fully virtuous agent would perform) are just not available to us.

Consistent with her denial of the claim that virtue ethics fails to provide any rules, Hursthouse could remind us of a further way in which an imperfect agent is able to figure out what he should do in certain circumstances. Given that each virtue generates a prescription, such as 'do what is charitable' or, 'do what is generous', an imperfect agent can grasp the concept of what it means to act 'charitably', or 'generously' (Hursthouse, 1999: p.35).

To gain a more specific idea of what it means to act charitably in a certain context, they could conceive of how a person who possessed charity would act, perhaps. In terms of gaining a more specific idea of what it means to act in accordance with environmental virtue, this option is ruled out, on account of the fact that we have few people who possess this virtue, on Hursthouse's view.

However, not only does each virtue generate a prescription according to Hursthouse, but each vice also generates a prohibition - a v-rule - such as 'do not do what is dishonest', or 'do not do what is uncharitable'. In terms of gaining a more specific idea of what it means to act in accordance with one of these vices, an imperfect agent could conceive of what it means to act dishonestly or uncharitably in certain contexts, by considering how a dishonest or uncharitable person would act in specific circumstances, and seek to avoid acting in that way. 
In relation to her claim that virtue ethicists seek to answer questions like "What should I do?" by reference to how some actual person who possessed the virtues to a high degree would act then, she could also add that virtue ethicists have another way of answering that question, namely, by making reference to how some actual person who possessed a vice to a high degree would act.

Can an imperfect agent conceive of a person who acts in accordance with environmental vice? While there might be a shortage of exemplars of environmental virtue, the same does not appear to be true for exemplars of environmental vice (or at very least, acts that exemplify environmental vice), particularly if Philip Cafaro's account is anything to go by. As discussed in chapter one, Cafaro's view is that the environmentally irresponsible behaviour of many Americans stems from environmental vices, including gluttony, arrogance, greed and apathy (2007: p.135). Making use of v-rules (namely vice-rules) in the way described above, the theory still generates the list of "obvious" prohibitions, which Hursthouse suggests are no less action guiding than those of other theories of environmental ethics. If my analysis here is correct, then Hursthouse succeeds in withstanding the epistemological challenge considered, and in doing so, her theory has the resources to provide action guidance, in the form of prohibitions, generated by v-rules.

\subsection{Conclusion}

An epistemological challenge to Hursthouse's account of right action is that an imperfect agent will not be able to determine what to do because they are not virtuous (Hursthouse, 1999: p.35). According to Hursthouse, virtue ethicists seek to answer questions like "What should I do?" by reference to how a person who possessed environmental virtue to a high degree would act, and that we also have very few exemplars of the relevant virtues (2007: p.168).

In my view, this is a concession that her theory fails to provide action guidance in such contexts. In this way, the epistemological challenge identified has implications for her environmental virtue ethics. Imperfect agents are unable to determine what to do in environmental contexts, because they are not environmentally virtuous, but also because there are no exemplars of the relevant virtues.

I suggested a strategy Hursthouse could take up in order respond to this challenge. If it could be shown that we do have exemplars of environmental virtue, I argued, Hursthouse could respond by pointing out that an imperfect agent would be able to 
determine what to do by seeking out the guidance of those exemplars, should this be possible. I drew upon Linda Zagzebski's motivation based virtue ethics, in an attempt to articulate a possible framework for identifying such agents, concluding that is not a plausible strategy for Hursthouse, as there is a risk that the two theories will turn out to be incompatible.

Instead I argued, however, that Hursthouse is able to meet the epistemological challenge in another way, by showing that virtue ethics can provide imperfect agents with action guidance in environmental contexts. To determine what they ought to do, an imperfect agent can conceive of how a person who possesses environmental vice would act in the relevant circumstances, and seek to avoid such behaviour. 


\section{Non-Virtuous Agents and the Qualified Agent Principle of Right Action}

\subsection{Introduction}

If Ronald Sandler is right that the division between the spheres of environmental ethics and interpersonal ethics is spurious (2007: p.86), then problems associated with the latter sphere will derivatively create problems for the former. In addition to the epistemological worries raised in the previous chapter then, Hursthouse faces a further series of damaging objections from interpersonal ethics, concerning nonvirtuous agents, and the worry that her principle of right action fails to generate the right result for such agents, in cases where the intuitively right action is not the characteristic behaviour of a virtuous person.

Robert Johnson (2003) poses three counter-examples to the idea of defining right action in terms of a completely virtuous agent, concluding that such an account fails to accommodate the fact that there are certain actions which seem appropriate for those of us who are less than virtuous, that no completely virtuous agent would ever do in the circumstances. Johnson's argument has received a considerable amount of critical attention, and provides several compelling reasons to think that the qualified agent principle may be inadequate.

Frans Svensson (2010) builds upon the objections made by Johnson, adding that a series of amended proposals to the qualified agent principle face further damaging objections. While Svensson's arguments on this point are strong, I will not discuss any of these proposals, on account of the fact that, if my defence of the qualified agent principle is adequate, such amendments will not be necessary in the first place. However, Svensson's criticisms of the qualified agent principle itself warrant serious consideration, particularly around Hursthouse's claim that we ought to draw a distinction between "morally right actions" and "right moral decisions". In sum, Svensson thinks such a move is counter-intuitive, and argues that Hurtsthouse fails to provide a substantive account for what counts as a "right moral decision" (2010). Ramon Das (N.d) has similar reservations about the strategy of severing the link between action guidance and action assessment, adding that such a move looks to be a concession that other, more structural objections to the theory cannot be met in any distinctively virtue ethical fashion (N.d: p.13). The major structural objection 
here, according to Das, is the charge that, by introducing the modifier 'characteristically', the qualified agent principle depends too heavily on non-virtue ethical concepts to explain its concept rightness, to the extent that it loses its distinctively virtue ethical character. In particular, Das argues such terms undermine, rather than support the key virtue ethical idea that moral rightness is fundamentally about inner states of character or motivation (N.d: p.10). Ronald Sandler (2007) also raises a couple of strong objections. First he argues that the qualified agent principle falls prey to what he describes as "the contextual problem", namely, the charge that virtuous agents, as human beings, are subject to a number of contextual factors, such as cognitive limitations, and trickery, to the extent that there may be cases where a virtuous agent does the intuitively wrong thing, even when acting in character. Second, Sandler argues that, for cases in which two different virtuous agents are placed in the same situation, the qualified agent principle falls prey to "the underdetermined problem", namely, the charge that it provides conflicting action guidance for both agents in question (2007: p.87). In this chapter, I will respond to each of the criticisms discussed. Against Johnson and Svensson, I contend that the counter-examples given fail to render the qualified agent principle implausible. In each case, I argue the agent in question ends up in circumstances no virtuous agent would be in, and that by following v-rules (namely vice-rules), each agent avoids doing what he ought not to do, even though this is not what a completely virtuous agent would do. In this way, virtue ethics can accommodate the common sense idea that we ought to become better people. Against Das, I contend that, even if it is the case that (allegedly) non-virtue ethical modifiers like 'characteristically' do not support the claim that rightness is fundamentally about inner states of character or motivation, it is not clear that this is the only distinctively virtue ethical feature at work in the qualified agent principle. Eudaimonia, to the extent that it is both unique to Aristotelian virtue ethics, and made explicit in the second premise of the theory's account of right action, looks to be another distinctively virtue ethical feature of the qualified agent principle of right action.

Against Sandler, I argue that "the contextual problem" fails to render the qualified agent principle implausible, for the same reason that Johnson's cases fail - virtue ethics still provides action guidance, even in situations where no virtuous agent would find themselves. Further, I argue that "the underdetermined problem" fails to 
render the qualified agent principle implausible on account of the fact that the principle itself allows for differences in the personalities, social roles, positions etc, and that it does not provide conflicting action guidance.

On these grounds then, I argue that the qualified agent principle, as a theory of action assessment, withstands the criticisms discussed.

\subsection{Non-Virtuous Agents and Self-Improvement: An Objection from Johnson}

\subsubsection{Three Counter-Examples}

Robert Johnson's central argument is a rejection of the claim that right actions are the actions that are characteristic of virtuous agents. In claiming that "an action is right iff it is what a virtuous agent would characteristically (i.e. acting in character) do", the theory generates the wrong result for non-virtuous agents, according to Johnson, in cases where the intuitively right action for such agents is an action that would be inappropriate for a completely virtuous agent to perform. The actions Johnson has in mind are self-improving actions, actions that a fully virtuous agent would not need to perform, on account of the fact that their being fully virtuous implies no further need for self-improvement, by hypothesis. In this way, he believes that theories which endorse such a claim are unable to explain moral distinctions between the behaviour of virtuous agents, and behaviour appropriate to those who ought to better themselves, leading to a surprising implication for virtue ethics - the idea the theory fails to account for our obligation to become better people. On the whole, his rejection of the qualified agent principle rests on the claim that there are some cases where it appears that the right thing to do for an ordinary person is not what a completely virtuous agent would do (2003).

In the first case, Johnson asks us to imagine a persistent liar, who decides he wants to rid himself of this habit. He resolves not to lie, but fails to begin with, caving into temptation. So he visits a therapist for advice on how to stop habitually lying, to which he is advised to record his lies, monitor his progress, and makes small, yet effective steps towards becoming a better person in this regard. If we have the intuition that the liar ought to better himself, and if we accept for the sake of argument that the liar ought to go about doing so in the ways described, the problem for the qualified agent principle in this example is that the actions described do not 
appear to be actions any completely virtuous agent would need to perform. The series of actions we want to describe as right actions, are not the characteristic behaviour of the completely virtuous agent, Johnson argues (2003) In the second case, Johnson asks us to imagine an agent who, as a result of his inadequate upbringing, struggles to do as he should, and who is at war with malicious and cowardly desires. He is able to overcome such desires, but not because of any inner motivation. Rather, he is meticulous in his planning of how he will act in situations where he will face potential struggles, and thinks of ways to avoid behaving badly in such situations. For example, when reasoning that he ought to help his elderly mother move houses, and, knowing that he will fail to overcome the temptation not to help if it strikes, he creates social support for behaving well reminding his friends that he won't be able to spend time with them, reminding them of what he ought to do instead, and so forth. Such behaviour, Johnson argues, can be described as a series of self-controlling actions, actions that are appropriate for the betterment of his character, and yet uncharacteristic of a completely virtuous agent, suggesting that the qualified agent principle is implausible on such grounds (2003). Johnson's third counter-example consists of a man who sees himself as having certain moral blindspots, resulting from his upbringing and culture. The man tries as much as possible to identify the area in which he lacks moral sensitivity, but, in failing to do so, seeks guidance from those who he takes to be more virtuous than him. While Johnson does not identify any specific area of consideration for the man in this example, it is worth noting that he considers racism, sexism and homophobia to be possible candidates for what might count as moral blind-spots. In any case, Johnson argues that the behaviour of the man in this example looks to be the morally right action, as it accords with the intuition that he should work to eliminate this blind-spot from his moral radar and thereby become a better person. Seeking out the guidance of others is however, as in the first two cases, not the characteristic behaviour of the completely virtuous agent, according to Johnson, rendering the qualified agent principle implausible, insofar as it does not generate the intuitively right result (2003).

\subsubsection{Action Guidance and Action Assessment: A Response to Johnson}

In response to Johnson, I argue that the cases he has presented here fail to show that the qualified agent principle is implausible. Indeed, the principle tells us that "an 
action is right iff it is what a virtuous agent would characteristically (i.e. acting in character) do in the circumstances" (Hursthouse, 1999: p.28) - that we should do what a virtuous agent would do in the circumstances. However, it does not follow from this prescription that it is possible for a virtuous agent to be in every set of circumstances. Circumstances arising from a morally wrong action are, by hypothesis, the result of an action that no virtuous agent could have performed. Thus, an imperfect agent deciding whether they should do what a virtuous agent would do in these circumstances simply does not have the option of doing what a virtuous agent would do. As a result, the qualified agent principle has not so much failed or been made implausible as a result of the fact that it fails to provide action guidance to the agent in question - the morally right action is simply not available to such agents. In cases like this, action guidance and action assessment have come apart. No action that an imperfect agent performs in such a situation can be correctly assessed as right action, by hypothesis (Hursthouse, 1999: 49-51). The question remains however: How have the agents in Johnson's cases arrived in circumstances where no virtuous agent would ever arrive in? Consider the following breakdown of separate questions likely to cross the mind of Johnson's reforming liar at each stage in the process, along with the action he subsequently performs:

t1: "Should I lie or tell the truth?" The reforming liar resolves to tell the truth, and succeeds

t2: "Should I lie or tell the truth?" The reforming liar resolves to tell the truth, and fails, caving into temptation

t3: "Should I visit a therapist or not?"

The reforming liar visits a therapist, who suggests possible strategies for improving his ability to tell the truth.

At $\mathrm{t} 1$, it can be asserted that the reforming liar performs the right action. A completely virtuous person is an honest person, and would (characteristically) act honestly in these circumstances - she would tell the truth. At t2, it can be asserted that the reforming liar does not perform the right action. A completely virtuous person is an honest person, and would not (characteristically) act dishonestly in these circumstances - she would not lie. At $\mathrm{t} 3$, whether or not the reforming liar performs the right action becomes a more contentious question. No virtuous agent would find themselves in circumstances requiring such a decision, because no 
virtuous agent would have acted dishonestly at $\mathrm{t} 2$. At $\mathrm{t} 3$, we could say that the qualified agent principle does provide an answer to the question "what is the morally right thing for the agent to do here?", namely that "there isn't one," (Hursthouse, 1999: p.50-51). With the necessary adjustments, this framework can be applied to the other two cases, indicating that the agent in question finds himself in a scenario where the morally right action is simply not available to him. Analogously, one could make the same claim about the self-controlling man - that his acts cannot be assessed as morally right actions, because no virtuous agent would have wound up in the same circumstances as the self-controlling man. Johnson's claim that no such web of self-controlling actions precedes the virtuous agent's performance of the virtuous action (2003) is, in this way, a concession to the fact that the self-controlling man is in circumstances no virtuous agent would be in.

And further, while my treatment of Johnson's third case has been limited, necessary adjustments can be made without too much difficulty. It must be noted though that Johnson commits himself to the claim that there are different senses in which one can be said to have a moral blind-spot. In most cases, he argues, blind spots in moral vision are not compatible with complete virtue, for instance, where the coward mistakenly judges the courageous person to be foolhardy. In such cases the man with the moral blind spot, who is anxious and unsure about whether he is making correct judgements makes the right decision in seeking out advice from those who better placed than himself. His action cannot be described as a morally right action because the completely virtuous agent would not be in the same circumstances - it would be impossible for him to possess the same shortcomings (Johnson, 2003). However, it is not likely that Johnson will be convinced with this picture of right action. In claiming that the principle generates the wrong result, he might point out that such a claim does not rest upon whether or not virtue ethics is inconsistent in how it assesses certain actions. Indeed, he seems to think there is something that the qualified agent principle fails to capture, something admirable about the actions being performed by each agent in question. Further, in line with his thinking throughout, he might argue that the gap between the characteristic behaviour of the virtuous and what he takes to be the appropriate action for the non-virtuous agent shows us that the qualified agent principle fails to provide an obligation for the nonvirtuous to become better people (Johnson, 2003).

It is worth making clear that the principle provides action guidance in cases where a 
non-virtuous agent finds themselves in circumstances a virtuous agent could conceivably arrive in. This is not the case for the examples identified by Johnson the principle ceases to be action guiding due to the fact that action guidance and action assessment come apart.

However, there is more than one way that the 'single prescription' of virtue ethics can be applied according to Hursthouse. As I discussed in chapter two, each virtue generates a prescription, such as 'Do what is honest', and each vice generates a prohibition, such as 'Do not do what is dishonest' (Hursthouse, 1999: p.36). These rules, v-rules, can be used to meet Johnson's objection, in the same way that Hursthouse goes about providing action guidance in a similar case.

The example she uses concerns a man who finds himself forced to decide whether to marry woman A or woman B, after impregnating both (1999: p. 50). The dilemma at hand is the result of a string of previous decisions no completely virtuous agent would have made. For the man deciding whether to marry A or B, Hursthouse claims that there is no morally right action that the agent could perform in these circumstances (1999: p.50).

Hursthouse also suggests that, for the case of the man deciding which woman to marry, a right decision can be made in the circumstances, even though it cannot be assessed as a morally right action. As she points out, it might be callous, or more irresponsible to abandon A but not to abandon B. It might also be the case that $\mathrm{B}$, unlike A, loses the desire to marry this man anyway. In this scenario, marrying A, rather than B, would be the morally right decision (1999: p.51).

If she is right about this, one could make the claim the reforming liar is obliged to better himself - that it is the morally right decision to do so - even though it is not the morally right action. One could do so by using v-rules to show that the reforming liar has an obligation to avoid acting out of vice. At $\mathrm{t} 3$, when the reforming liar asks himself whether he should visit a therapist, the morally right decision for him would be "yes", insofar as he would be performing the action that is less cowardly, perhaps, or in any case, less expressive of the relevant vice.

\section{3. 'Right Actions' and 'Right Moral Decisions': Addressing Svensson}

On these points, it is appropriate to introduce a related objection from Svensson, concerning Hursthouse's distinction between "right action", and "right moral decision". Primarily, Svensson finds it counter-intuitive for Hursthouse to say on the 
one hand that the man's decision to marry $\mathrm{A}$ is the right decision, even though it is not the morally right action. Further, and perhaps more compellingly, he argues that Hursthouse does not provide a substantive account for what counts as a "right moral decision". The only suggestion that can be found, according to Svensson, is that a decision is right if and only if it is what a completely virtuous agent would decide in the circumstances, something that will not be adequate, insofar as Hursthouse would be "granting that there might be right decisions to make even in circumstances no virtuous agent could be in" (Svensson, 2010).

Against Hursthouse, this looks to be a strong objection, but I contend she is able to address it. First, we need to take into account the fact that the suggestion at hand had been made with irresolvable and tragic dilemmas in mind specifically. Contrary to Svensson's claim then, Hursthouse does indeed appear to be granting that virtuous agents would be in situations of this kind, situations from which "even a virtuous agent cannot emerge with her life unmarred" (Hursthouse, 1999: p.75). In this way, it is not clear that any of Johnson's cases would be considered irresolvable or tragic dilemmas, on Hursthouse's account. Further, it needs to be stressed that Hursthouse commits no contradiction here - it is apparent that Svensson has wrongly attributed her account of what counts as a right moral decision in tragic dilemmas, elsewhere acknowledged as a qualification to deal with exceptional cases to her account of what counts as a right moral decision in other cases.

Svensson may concede this point and yet maintain that Hursthouse provides no account for what counts as a "morally right decision" in situations that no virtuous agent would find themselves in, such as the case of the two-timing lover. Further, in the interests of consistency, it might be argued that the onus is on myself to provide an account of what counts as a "morally right decision" for cases in which no virtuous agent would find themselves, insofar as I have placed much of the weight of my response to Johnson on this term.

In terms of constructing a more substantive account of what counts as a morally right decision, it is worth considering two things. First, Hursthouse makes explicit the claim that action guidance and action assessment come apart in certain situations (1999: p.51). Consider these two questions: (A) "Should I do act x?", and (B) "was x the morally right act?” As I see it, while the respective answers may well be consistent with one another in most cases, there is no logical reason to suggest that they need to be so, and this seems to be the point that the two-timing lover example 
is pressing. In response to question (A) Hursthouse's theory would presumably say "Yes" the man in question should marry woman A, even though the answer to (B) would be "No", marrying woman A is not the morally right act (i.e. it is not what a completely virtuous agent would characteristically do in the circumstances). Further, ethical life does not appear to be as black and white as simply considering our options to be "morally right action" and "morally wrong action", certainly not on Hursthouse's view, and almost certainly not on the view of other, non-virtue ethical moral philosophers. On Hursthouse's view, it is worth noting that every virtue-rule comes with a corresponding vice-prohibition, providing us with an account of what constitutes morally wrong action - "Do not do what is cruel/unjust/etc" (Hursthouse, 1999: p.35). Of the behaviour of the individuals in each of Johnson's examples, it appears to be incorrect to describe such actions as wrong actions - that is, actions that are expressive of vice - there appears to be a matter of degree at play, in which such actions will presumably fall somewhere in between.

As Liezl van Zyl points out, Hursthouse leaves room in her account to say that a morally right decision is the action that which the agent "ought" to perform, even though it is not the right action, in the sense of being a "good" or "admirable" action. Van Zyl does not use the term "morally right decision" to describe the relevant action, but offers a fairly simple solution about where we can find the obligations that provide guidance to non-virtuous agents in such situations. In a situation where a non-virtuous agent finds themselves in circumstances which no virtuous agent would, a non-virtuous agent ought not to do what is cruel, callous or unjust, following the prohibition generated by the relevant v-rule (2011) Further, Hursthouse's distinction between action assessment and action guidance allows us to capture a further intuition. The student who is late to finish their essay is worthy of some degree of praise, according to van Zyl, even though they should have worked harder during the semester, as a virtuous agent would have (2011). I argue then that Hursthouse is able to provide a substantive account for what counts as a "right moral decision", and withstand Svensson's criticisms on this point. As I pointed out earlier, Svensson's objection partly rested upon the claim that Hursthouse's only suggestion was the solution proposed for irresolvable dilemmas, which upon further analysis, is not the case. However, Hursthouse is still left to deal with his claim that it is counter-intuitive to say that the two timing lover acts wrongly in marrying A. I contend that Svensson's objection does not render her account 
inadequate, primarily on account of the fact that the claim itself rests on no further argument.

More importantly though, if Svensson is to suggest that Hursthouse cannot draw a distinction between acting well (in terms of performing the right action), and doing what one morally ought to do, then, if we are to be consistent with this idea, other non-virtue ethical moral theories will also be prevented from doing so. Such a restriction would put all moral theorists in trouble, insofar as it would remove their ability to find a place for supererogatory acts. While it is not something I wish to focus on in any great detail, much emphasis has been placed on the idea that moral theories should be able to distinguish between supererogatory acts (that is, acts that are praiseworthy, but not morally obligatory), and morally mandatory acts (Heyd, 1980). While it is highly unlikely, even if Svensson were to bite the bullet on this point, and claim that such a restriction ought to be maintained, virtue ethics, at very least, does not look to be in any worse a position for taking on Hursthouse's suggestion that we treat action guidance and action assessment separately in cases like that of the two timing lover.

I argue then that Hursthouse is able to address Svensson's objection unproblematically. Further, if my analysis here is correct, Johnson's counterexamples can be accounted for in the same way as Hursthouse can account for the case of the two-timing lover: the reforming liar, the self-controlling man, and the man with moral blind-spots all do what they are morally ought to do, even if they do not perform the right action - they ought not to do what is vicious.

Seen in this way, the distinction between action guidance and action assessment shows us that, in cases where the two come apart, the qualified agent principle is in no way implausible as a theory of action assessment. The theory still tells us what the right action is, even if such a course of action is not available to a less than virtuous agent. Even in such cases, virtue ethics still provides non-virtuous agents with action guidance, namely through the prohibitions generated by v-rules. However, some critics may point out that by emphasizing the fact that action guidance and action assessment come apart, Hursthouse's account is open to other damaging objections.

\subsection{Distinctively Virtue Ethical Right Action and Eudaimonia: Addressing Das}


On this point then, it is important to consider a few related criticisms from Ramon Das (N.d) who is, on the whole, doubtful about the prospect of virtue ethics being able to provide a distinctively virtue ethical account of right action (N.d: p.4). Like Svensson, Das thinks that the virtue ethical strategy of severing the connection between rightness and action guidance is unsatisfying, and a sign of theoretical desperation. Importantly, he adds that this strategy, far from being an attempt to rebut structural objections made against the theory, is rather a concession that they cannot be met in any distinctively virtue ethical fashion (Das, N.d: p.13). The major structural objection he makes against Hursthouse's account, in my view, is the charge that the qualified agent principle of right action depends too heavily upon non-virtue ethical modifiers to generate the intuitively right result, in problem cases (N.d: p.10) According to Das, the key virtue ethical idea is that "moral rightness is fundamentaly a matter of conformity to an agent's inner states of character or motive", an idea which he thinks is undermined by the various modifications to the theory (2013: p.10). Distinguishing between "pure" virtue ethical theories and "modified" virtue ethical theories, Das presents Hursthouse's account of right action in Virtue Theory and Abortion (1991), as an example of the former, with the label PV, and her account of right action given in On Virtue Ethics (1999) as an example of the latter, with the label, MV, setting them out as follows:

$P V \quad$ An act is right if and only if it is what a virtuous agent would do in the circumstances

$M V \quad$ An act is right if and only if it is what a virtuous agent would characteristically (i.e. acting in character) do in the circumstances (Das, N.d: p.9).

For $M V$, Das argues that the term 'characteristically' functions as a built in exception for the theory in cases where its distinctively virtue-ethical criterion of rightness brings about the intuitively wrong result. The modifier 'characteristically', Das suggests, seems to undermine, rather than support the key virtue ethical idea mentioned above, on account of the fact that its inclusion in $M V$ admits of the fact that, sometimes, moral rightness does not conform to inner states of character or motive (N.d: p.10).

In response, I argue that, while Das raises some strong points here, there is nothing, by his own admission, that renders the qualified agent implausible per se, even if one is to draw a line between action guidance and action assessment. As he puts it, the 
question instead centres around whether or not the qualified agent principle is sufficiently virtue ethical, something he disputes on the grounds that modified versions of the theory look to turn on key terms like 'characteristically' that are not distinctively virtue ethical in nature.

However, there is a slight sense of arbitrariness around two of the key concepts involved in his arguments here, first, on what it means for something to be distinctively virtue ethical, and secondly on whether the claim that "moral rightness is fundamentally a matter of conformity to an agent's inner states of character or motive" (Das, N.d: p.10), is the only distinctively virtue ethical idea. The suggestion seems to be that the second claim is the only thing that sets a theory apart as a distinctively virtue ethical theory, but it is unclear why this ought to be so. It is not clear why eudaimonia, for example ought not to be considered a "distinctively" virtue ethical concept for Hursthouse, not least for the fact that rival accounts do not endorse it, but also on account of the fact that a eudaimonistic assumption is implicit in the qualified agent principle of right action. By this latter claim, I mean that, by introducing the concept of the virtuous agent, the principle itself implicitly introduces the idea that a virtuous agent possesses the virtues, which (at least on an Aristotelian interpretation) implicitly introduces the idea that a virtue is a character trait that a human being needs for flourishing, or eudaimonia (Hurshouse, 1999: p.29).

It is at least possible then, for a defender of the principle to agree with what Das has to say about moral rightness sometimes not conforming with inner states of character or motives, and yet hold that eudaimonia is nonetheless a distinctively virtue ethical concept at work in the qualified agent principle.

\subsection{Contextual Factors and Conflicting Action Guidance: Addressing Sandler}

In the final part of this chapter, I will address a couple of objections against the qualified agent principle raised by Ronald Sandler (2007), that are somewhat different to the style of criticisms made by the authors discussed above, but raise important problems for the principle all the same. First is what Sandler describes as "The Contextual Problem" for the qualified agent principle of right action (p.89). In short, Sandler argues, it is sometimes the case that contextual factors such as sleepdeprivation, trickery and ignorance, can lead a virtuous person to do what seems 
intuitively wrong, even when she is acting in character. As he points out, the qualified agent principle is required to define right action in terms of actual virtuous agents, which is problematic in the sense that actual virtuous agents are actual humans. All virtuous persons are physically, emotionally and cognitively finite, according to Sandler, and are therefore open to external pressures which can compromise the appropriateness of the actions performed by such agents in these circumstances, such as ignorance and luck. What an agent should do then, whether they are virtuous or non-virtuous, is a function of that agent's character, knowledge and so forth, and therefore "one person's actions (or desires or beliefs) are not always going to be an appropriate guide for others, even if (and sometimes because) she is virtuous" (2007: p.89-90).

To my mind, it is difficult to see how this is objection casts doubt over the qualified agent principle at all, when one considers the way in which it has been fleshed out in terms of Johnson's reformulation of Hursthouse's qualified agent principle. As I understand it, the qualified agent principle does not imply that the appropriate course of action is going to be an instantiation of the behaviour of one single completely virtuous person, which Sandler's account seems to suggest. Even though the concept of the completely virtuous agent should, according to Johnson, be thought of as a human, rather than a God-like ideal (2003), it is still cashed out in terms of an ideal, rather than actual agent, which is problematic for Sandler's claims on this point. Further, in response to the claim that a virtuous agent's actions might be an inappropriate guide to the non-virtuous, following from the claims made earlier, v-rules such as "do not do what is dishonest, cruel, unjust etc" still tell me what I ought to do, even in circumstances which no virtuous agent would find themselves in.

Despite the problems identified here, there is a further objection that can be raised against Sandler's Contextual Problem for qualified agent principles of right action. In line with the discussions earlier, recall the purpose the "characteristically" modifier serves for such accounts of right action. According to Das, the term "characteristically" is working as a built-in exception for cases where the theory gets the intuitively wrong result. I argue that the contextual factors described by Sandler - sleep-deprivation, trickery and ignorance - could be accounted for as examples of such cases where the theory gets the intuitively wrong result. In this way, I am questioning Sandler's assumption that a completely virtuous agent can perform 
intuitively wrong actions, while acting in character, on the grounds that the "characteristically" modifier rules out this possibility by hypothesis. On these grounds then, so long as my responses to Das made earlier are decisive, I argue that the contextual problem is not a decisive objection to the qualified agent principle. Another objection to the qualified agent principle from Sandler is what he describes as "The Underdetermined Problem". What an actual virtuous person would do in certain circumstances, according to Sandler, would depend upon her abilities, commitments, positions etc, and for this reason, when two virtuous persons are placed in the same situation and both acting from virtue, they might nonetheless do different things. He uses the example of a child being swept away in a riptide, to show that, what we assess as the right action depends upon crucial facts about the agent's character, such as whether or not the agent can swim, rather than the behaviour of a completely virtuous person. For a trained life-guard, it would be wrong, Sandler argues, to waste time looking for help, when she can dive in and make the rescue herself, even though other virtuous agents would call for help (2007: p.87-88).

In response, I argue that Sandler's example fails to show that the prescription "do what a virtuous agent would characteristically do in the circumstances" gives no action guidance, or conflicting action guidance. It does not follow that the v-rule "do what is charitable" prescribes the course of action "dive into the sea and save the child" or "call for help" directly. To be charitable is to help others when doing so would be at little cost to oneself. There is no contradiction then, in pointing out that an agent in this particular situation will need to take into account their abilities, limitations, and ultimately, their experiences in various social roles, when they decide to do what is charitable. And the story is the same for virtuous agents. Any virtuous person will do everything in their power to ensure that the child does not drown, but that does not entail that they need to make the same set of decisions to realize that goal. A morally virtuous life-guard, aware of her swimming prowess will reason that the best way of realizing that goal is to jump in and save her. A wheelchair bound, morally virtuous retiree, aware of her inability to swim at all, will reason that the best way to realize that goal is to call somebody for help. Despite being a critic of the qualified agent principle of right action, Johnson makes a similar observation about the qualified agent principle, and the nature of virtues, which squares well with the points raised. Two equally charitable agents will go 
about acting charitably in ways appropriate to their character, he claims. It would be appropriate for a charitable introvert to quietly prepare soup at a soup kitchen, whereas a charitable extrovert would be better suited to organizing social events to aid the plight of the less fortunate (2003). In light of the forgoing arguments then, I contend that the underdetermined problem, as presented by Sandler, is not a decisive objection against the qualified agent principle of right action.

\subsection{Conclusion}

In sum, my view is that, despite their merits, none of the criticisms discussed succeeds in refuting the qualified agent principle for virtue ethical right action, as a theory of action assessment.

For Johnson, I argue that he fails to render the qualified agent principle implausible for several compelling reasons. First, upon closer inspection, it is evident that his argument faces problems of its own, namely in the set-up of the counter-examples. For instance, in the case the reforming liar, it is evident that no completely virtuous agent would find themselves needing to decide whether to visit a therapist, because no completely virtuous agent would lie in the first place.

Indeed the actions of the reforming liar and the corresponding cases cannot be assessed as morally right actions - they are not actions that a completely virtuous agent would perform. This is no fault of the qualified agent principle, however, on account of the fact that a completely virtuous agent would not get herself into such circumstances in the first place. In such cases, action guidance and action assessment have come apart. In this way, virtue ethics, interpreted correctly, can successfully accommodate the common sense idea that we ought to become better people. In each case, the agent at hand does what he ought to do - he avoids doing what is vicious.

The claim that the agent, does what he ought to do, even though it is not the right action, along with the subsequent claim that action guidance and action assessment come apart in certain scenarios, invites the objections made by Svensson and Das to some extent, but if my analysis is correct, virtue ethicists are able to put forward compelling responses to such. Much of Svensson's doubt stems from the claim that it is counter-intuitive to make such a move, which, runs into problems of its own. In particular, if virtue ethics is not allowed to draw a distinction between action guidance and action assessment, then I argue that neither should other theories be 
allowed to draw such a distinction. Such a claim is questionable then, as it would prevent all moral theories from finding a place for supererogatory acts.

For, Das, even if terms like 'characteristically' are doing much of the work in explaining the theory's account of rightness in some cases, this does not, by his own admission, make the qualified agent principle implausible. Furthermore, even if it is the case that such terms are not supporting the virtue ethical idea that moral rightness is fundamentally about inner states, this does not entail that the qualified agent principle loses its distinctively virtue ethical character. Insofar as it forms one of the implicit premises in the qualified agent principle of right action, but also on account of the fact that the term is not endorsed by rival theories, I argue that the concept of eudamonia is a distinctive feature of Aristotelian virtue ethics. And for Sandler, in the same way that Johnson's cases were argued to be problematic, I maintain that the contextual problem is not a decisive objection to the qualified agent principle on this front, namely due to the fact that it provides an account of what one ought to do, even in situations where no virtuous person would find themselves. Similarly, the underdetermined problem, I argue, turns out to be not so much of a problem at all for the qualified agent principle, on account of the fact that the theory does not provide conflicting action guidance in the relevant case. 


\section{Action Guidance and Environmental Virtue Ethics}

\subsection{Introduction}

In addition to concerns around whether virtue-oriented ethical theories can provide a plausible account of right action (as a theory of action assessment), further issues surface around how reliable such theories are in providing action guidance on practical issues (Louden, 1984; Sandler, 2007: p.97).

Particularized to environmental ethics, a further worry is that virtue oriented theories will be insufficiently action guiding on related issues, according to Ronald Sandler. Theories of this kind might well succeed in providing a substantive account of the character traits people ought to cultivate, regarding the environment, and will perhaps derivatively give an indication of the general environmental behaviours they ought to engage in. However, as Sandler suggests, it might be argued that such theories will fail to provide specific guidance in concrete situations, or on concrete issues (2007: p.97).

In this chapter, I will respond to both general concerns raised above, starting with a family of objections made by Robert Louden (1984). The goal here is to articulate the importance of action guidance to moral theory generally, and the perceived shortcomings of virtue ethics on this front. In doing so, this will set the scene for the latter part of the chapter, where I consider what is required of a theory of environmental ethics, in terms of action guidance. First, Louden argues that virtue ethics places too high an emphasis on long-term characteristic patterns of behaviour, to the point that it fails to recognize the importance of discrete acts. Second, he argues that the theory cannot provide a satisfying answer to the question "What should I do?" Even though the theory tells us to "do what a virtuous agent would do," such an answer provides us with limited action guidance, according to Louden, insofar as it is often hard to fathom what a hypothetical moral exemplar would do in particular cases. Third, and in relation to the previous point, Louden points out that to possess a virtue, one must also possess the skill of practical reason, along with situation specific "know-how". He thinks that such abilities are not transferrable to non-virtuous agents as part of a decision procedure, meaning that the theory is in trouble insofar as it cannot provide us with clear action guidance in concrete situations (Louden, 1984).

I consider two responses to Louden's objections here. First, in outlining potential 
problems for an environmental virtue ethics, Geoffrey Frasz offers a direct response to Louden, questioning whether environmental virtue ethicists should be required to abstract agents from the acts they perform. Our environmental heroes are not hypothetical exemplars leading abstract lives, according to Frasz. They are real agents who act concretely, and, rather than telling us what to do or how to live, they set examples of living that embody environmental insights (Frasz, 1993). As a means of showing how virtue ethics can provide concrete, situation-specific action guidance, Frasz's response looks to be promising, but I will show that it is ultimately problematic, for the reason that it runs the risk of affording privilege to narrow beliefs about who is an environmentally virtuous agent.

Instead, I consider the ways in which Hursthouse's theory provides more decisive responses to Louden on these charges. In particular, it appears that her approach of assessing acts in abstraction from the acting agents, by the use of v-rules, is a useful response to Louden's first objection. In response to the second I argue that Hursthouse's theory does not put itself in a position where it cannot structurally provide an answer to the question “what should I do?” (1999: p.29).

To meet Louden's third objection, I consider a response from Julia Annas. The idea that we should seek to have a decision procedure to resolve all of our ethical dilemmas - one that is accessible to anyone with the right skills - is absurd, on Annas's view, on account of the fact that it removes an important sense in which agents are praiseworthy or blameworthy for their actions (2004).

In the latter part of this chapter, I will consider the ways in which Hursthouse's environmental virtue ethics fares in relation to the second general worry raised earlier. As I have been operating with Sandler's assumption that a theory of environmental ethics must provide an account of the norms of action which govern our human relationship with the natural environment, I will elaborate on what is required in this regard, by discussing what is required of an adequate environmental ethic, focussing in particular on the claim that an adequate environmental ethic must provide "action and policy guidance in concrete situations involving individual or community interactions or relationships with the natural environment" (Sandler, 2007: p.108).

In regard to this requirement, Sandler considers a specific objection that critics of virtue oriented approaches to environmental ethics might raise, namely the objection which holds that "A virtue oriented approach cannot provide sufficient guidance on 
concrete environmental problems or issues" (Sandler, 2007: p.110). One potential reply, inspired by Annas, but consistent with Hursthouse, is that the expectation that we provide concrete action guidance at all costs creates the same sorts of problems raised earlier. If it is assumed that theories of environmental ethics require a decision procedure, this picture of ethical theory also faces the problems raised by Annas, I contend.

In case this objection is not decisive, I consider a further response on behalf of Hursthouse, namely the claim that her theory is not ruled out from providing the sort of action guidance provided by Sandler's virtue oriented approach to environmental decision making.

My goal for this chapter is to show that critics of Aristotelian virtue ethics are not warranted in rejecting the theory as one that fails to provide action guidance. In doing so, I aim to show that the theory is in a position to meet the action guidance adequacy condition for environmental ethics. I will do so by showing that the theory is not inconsistent with Sandler's virtue oriented approach to environmental decision making, in the relevant respects. The only significant difference, I argue, is that Hursthouse's theory provides a different account of right action, one that is defensible for the reasons given in the previous chapter, and one which is compatible with the arguments made by Sandler regarding action guidance.

\subsection{Can Virtue Ethics Provide Concrete Action Guidance?}

\subsubsection{Three Objections from Louden}

To begin, I will consider and respond to a family of general action guidance objections against virtue-oriented ethical theories. One common objection is that such theories fail to tell us what to do, a charge that brings into question the usefulness of such theories on issues in applied ethics. An early form of this objection can be found in Robert Louden (1984) who argues that, by focussing on good and bad agents, rather than right or wrong acts, virtue theorists are forced to de-emphasize discrete acts, and instead favour long-term characteristic patterns of behaviour. Consequently, Geoffrey Frasz adds that Louden's criticisms here have implications for environmental virtue ethics, particularly the charge that virtue ethics cannot assess acts in abstraction from the acting agents (Frasz, 1993).

With its emphasis on the question "What person ought I to be?" virtue ethics is also 
structurally unable to provide us with answers to the question "What ought I to do?" according to Louden. We should do what the virtuous agent would do, he recognizes, but contends that "it is not always easy to fathom what a hypothetical moral exemplar would do were he in our shoes, and sometimes even he will act out of character" (1984).

Further, it might be pointed out that virtue ethicists, by their own admission, are committed to the view that virtues are not simply dispositions to perform certain kinds of actions, but also involve skills of perception and situation specific "knowhow". While this appears to be an advantage of the theory, Louden suggests that it may in fact turn out to be problematic. He thinks that the skills of moral perception, and practical reason are "not completely routinizable, and so cannot be transferred from agent to agent as any sort of decision procedure 'package deal'” (1984: p.229), which is problematic in the sense that we can expect only a very limited amount of advice on moral quandaries from virtue ethical approaches.

\subsubsection{Environmental Heroes and Concrete Acts: A Response from Frasz}

It is worth considering a direct response to Louden's criticisms from Geoffrey Frasz, one which places such criticisms squarely within the sphere of environmental ethics. While admitting that the kind of guidance given by charismatic environmental figures is vague, Frasz notes that such figures deliberately avoid telling others how to act, and instead try to set examples of living which embody environmental insights in doing so. To meet Louden's charge that virtue ethics cannot assess acts in abstraction from the agents that perform them, Frasz suggests that virtue ethicists should not abstract environmentally virtuous agents from the acts they perform. He argues:

These heroes are not living abstract lives. They act concretely. They are not ethicists abstracted from their ethical rules. They are not agents who separate themselves out from nature. Indeed it is precisely this separation that has contributed to the alienation from nature that is common to our culture.

Viewed in this way, environmental virtue ethics turns what at first seems like a problem area into an advantage over other theories (Frasz, 1993: p.262) Frasz's argument here is an interesting juxtaposition to Louden's picture of virtue ethics in relation to dilemmas in applied ethics. In focussing on actual agents and the actions they perform, the style of virtue ethics described by Frasz seems to allow 
the theory to maintain its focus on long-term patterns of characteristic behaviour while compromising nothing in terms of its ability to provide action guidance. On Frasz's view then, the advantage of not abstracting agents from the acts that they perform is that such a move does not necessarily rule virtue ethics out from providing concrete, situation-specific action guidance: the actions of agents we take to exemplify particular virtues (in this case, environmental virtues) are concrete actions.

Ultimately though, I do not find this particular response from Frasz persuasive. It might be true that the agents we are concerned with "act concretely" as he points out. However, if such acts are thought to be action-guiding, there needs to be some assurance that the agents performing them possess the relevant virtues. By referring to charismatic environmental figures as the sorts of agents we ought not to assess in abstraction from the acts they perform, Frasz puts a lot of the weight of his argument on such figures as being exemplary of the relevant virtues.

The danger here for Frasz is that his response appears to take on the problems associated with those environmental exemplar approaches discussed in chapter two. According to Sandler, such approaches afford privilege to obtaining beliefs about who is environmentally virtuous, beliefs that run the risk of being distorted, narrow or otherwise inadequate. Further, these approaches do not provide the resources to adjudicate between competing views about who is environmentally virtuous. For example, North American environmentalists will have different views to ranchers and sportsmen about who counts as an environmental hero, as will people from other parts of the world (Sandler, 2007: p.10).

Why then, might Frasz's response face similar problems? On Frasz's view, environmental virtue ethicists ought not to abstract environmental heroes from the actions they perform, and the sorts of environmental heroes he has in mind include Aldo Leopold, John Muir, and David Brower (1993). In my view then, Frasz's argument is grounded in a firm prior conception of who is environmentally virtuous, lending itself to the problems identified by Sandler.

In many ways though, Frasz is aware of the potential issues facing a view that seeks to identify model persons, rather than model cases, pointing out that a potential danger of environmental virtue ethics is that it can "blind us to the vices of environmentally virtuous persons by focusing on their overall character, when immediate, common-sense wisdom, competent technical knowledge is urgently 
needed to deal with the decisions at hand" (Frasz, 1993).

Further though, he points out that environmental virtue ethics requires a moral psychology showing that it is possible to become an environmentally virtuous person (Frasz, 1993). In response then, Frasz could point out that the foregoing arguments do not necessarily prevent him from being able to construct a more substantive account of the environmentally virtuous agent, as a way of showing that the behaviour of such agents is exemplary.

\subsubsection{A Response on Behalf of Hursthouse}

In my view, we can avoid problems identified by Louden and Frasz altogether, perhaps more compellingly, by showing that acts can be assessed in abstraction from the agents that perform them, in a virtue ethical theory. In this way then, let us consider Louden's objections in relation to Hursthouse's account. As Louden's objections are geared towards virtue ethics in general, rather than issues facing environmental virtue ethics, the following discussion will not cover Hursthouse's arguments in "Environmental Virtue Ethics" (2007), though I will discuss the problems facing her arguments in that paper towards the end of this chapter. I argued in earlier chapters that Hursthouse succeeds in dispelling the misconception that virtue ethics is exclusively concerned with agents, and not concerned at all with acts, and takes into account the fact that virtuous agents sometimes act out of character. The theory does not focus on long-term characteristic patterns of behaviour at the expense of atomic acts - its account of right action provides an assessment of the latter (Hursthouse, 1999).

These features of Hursthouse's view, I think, provide the means by which a defender of virtue ethics can meet the first two broad criticisms made by Louden. Virtue ethics is not structurally unable to provide an answer to the question "What ought I to do?”, and nor is it prevented from telling us what to do in a way that only makes vague reference to a hypothetical moral exemplar. We can, as Hursthouse does, provide action guiding principles that take on a similar structural form as the rules that appear on a deontologist's list. These action guiding principles, which Hursthouse describes as "v-rules", provide clear prescriptions of what to do, and of what not to do, corresponding to each virtue and vice. We ought to "Do what is honest/charitable/courageous", and to "Do not do what is dishonest/cruel/cowardly" and so forth (1999: p.51). 
Further, Hursthouse is in a position to deal with the worry raised by Frasz earlier, concerning the risk of virtue ethics blinding us to the vices of "virtuous persons" (1993). Her theory of right action, consistent with the doctrine of the unity of the virtues, requires us to conceive of an agent that is fully virtuous (i.e. honest, charitable, just, etc) (1999: p.73). By hypothesis then, Hursthouse rules out the possibility of a virtuous agent possessing any vices.

Even if Hursthouse's arguments on these points prove to be decisive, it is the third criticism from Louden that seems to be a lot more problematic for virtue ethics, particularly when we think about what it has to say about issues in applied ethics. On the qualified agent principle, a right action is what a virtuous agent would characteristically do in the circumstances. A virtuous agent is a person who possesses certain character traits, namely the virtues. What makes an action right then and thus what one ought to do, (excluding situations in which no virtuous agent would find themselves) is very much contingent upon the nature of virtues themselves.

If, as Louden recognizes, a virtue is more than simply a disposition to perform certain actions, and what it means to act virtuously in certain situations can only be determined as a result of excellent moral perception or practical reasoning, then the theory seems to be unhelpfully vague for concrete issues. It might be argued that the relevant skills here are simply not available to non-virtuous agents, and indeed that they could not, as Louden points out, be transferred to non-virtuous agents as part of a “one-size fits all” decision procedure (1984).

\subsubsection{Is Concrete Action Guidance Desirable? A Response from Annas}

Against this charge, one response might be to question whether a "one-size fits all" decision procedure is a desirable aim for moral theory in the first place. According to Liezl van Zyl, this line of thinking is the typical response virtue ethicists call upon, when the theory comes under threat for its perceived failure to provide a single action-guiding principle. Critics of virtue ethics often argue that, for a moral theory, "there must be a single (if not a simple) action guidance principle, for if it provides more than one, it is possible for them to give conflicting advice” (van Zyl, 2011: p.88). The view held by some contemporary virtue ethicists, including Hursthouse and Julia Annas, is that a theory of right action which seeks to provide a single actionguiding principle, and derive more specific rules from it, is not a desirable model for 
ethical theory.

On Annas's view, the idea that we should want a theory of right action that tells anybody what to do seems to leave out something important about the making of moral decisions, namely the sense in which we are making our own decisions. With regard to the discomfort she has around the idea of being "told what to do" by a theory of right action, and against views of this sort, Annas writes:

Theories of right action are supposed to be practical, to give us specific directions. Since it is taken to be a fault in such a theory to be vague or unspecific, the desired result has to be, precisely, my being told what to do here and now, Yes or No. Reasons to back this up and enlarge my understanding of why the answer is Yes, on this occasion, rather than No, do not remove this feature. So the original discomfort remains: Do we really want a moral theory to tell us what to do? Aren't we losing an important sense in which we should be making our own decisions? (Annas, 2004: p.65).

One interesting point to note about Annas's argument is her suggestion surrounding a certain expectation of non-virtue ethicists, namely the expectation that a moral theory should avoid being vague or unspecific at all costs. The suggestion from Annas here is that this strict requirement carries undesirable consequences with it. That we need to instead provide supposedly concrete, "Yes or No" directives lends itself to a further problem, she thinks. On the strength of her argument, the problem for theories that make use of a decision procedure approach is that they fail to capture the idea that there is something praiseworthy or blameworthy about the agent who performs a given action. In a technical case (e.g. a computer related case), if an agent comes to realize that the action they performed earlier was the wrong thing to do, they can point out that they either got the manual wrong, or that the manual was wrong, without needing to reflect upon why they made the wrong decision. In a moral dilemma, however, Annas thinks there is something problematic in applying an analogous line of thinking, as the decision procedure approach appears to. When an agent performs a morally wrong action, the thought that the agent either gets the theory wrong, or that the theory was wrong is inadequate, according to Annas, as there is no worry as to that agent's making the wrong decision (2004).

In any case, the discomfort identified by Annas persists even when we conceive of cases in which the theory generates the right result, the agent is following the theory 
correctly, and the point of their following the theory was to be told what to do. She outlines one such case:

Suppose (unrealistically!) someone always does what his mother tells him to do. He always follows her orders; if he fails to do so he feels guilt, regret and so on. We take this to be immature, a case of arrested development; at his age, we say, he should be making his own decisions. Now, why should this picture become all right when we replace Mom by a decision procedure? Presumably a decision procedure, supported by a theory of right action, can be expected to be correct more often, and more reliably, than Mom can; but how could this remove the worry? (Annas, 2004: p.65)

On the face of it then, it looks as though Annas's worry is that a decision procedure, operating with a single action-guiding principle, is problematic in the same way that seeking out guidance from one's mother is problematic. Such a way of thinking provides no assessment of the agent performing the act, the qualities they possess, and ultimately this seems to lead us to undermine the importance of whether or not agents themselves make a right moral decision.

The emphasis virtue ethics places on agents and personal development seems to work in the theory's favour in this way. On her view, becoming virtuous is, in some ways, similar to the acquisition of a practical skill. A virtue is practical, in the sense that it requires a general understanding of the relevant field, and further, it involves an important aspect of other practical skills, the process of learning, from the state of being a learner, to the state of being an expert (2004). If learning to be moral is like acquiring a practical skill in this way, an attractive feature of virtue ethics is that it rejects as absurd the idea that a single piece of advice would work for everyone, as a means of becoming a better person. If so, this is an advantage of virtue ethics, over approaches to ethical theory that favour a decision procedure.

Annas points out several other problems with the line of thinking entailed by theories of right action which seek to provide a decision procedure. At this point, however, I will bring the focus back to Louden, on account of the fact that the problems identified earlier seem to be the strongest objections against such a view. Against Louden's criticisms, one could accept the claim that non-virtuous agents do not possess the skills of moral perception and practical reason of their virtuous counterparts, and yet maintain that the theory still leaves several options open in terms of their ability to discern what they ought to do. Following Hursthouse, when 
faced with a difficult scenario, a non-virtuous agent can seek out the advice of a virtuous agent, should this be possible (Hursthouse, 1999: p.51).

Alternatively, a non-virtuous agent could figure out what they ought to do without seeking out the advice of a virtuous agent. By hypothesis, a fully virtuous agent characteristically does what is honest, charitable, true to her word and so forth, and does not do what is dishonest, uncharitable, untrue to her word, and so forth. To determine what they ought to do then, a non-virtuous agent could follow the prescriptions or prohibitions (v-rules) generated by the relevant virtues or vices, being careful to conceive of a fully virtuous agent in doing so, in order to avoid conflict between the virtues (Hursthouse, 1999: p.51).

Further, following Annas, one could point out that, while the theory leaves these options available at the expense of providing a "one-size fits all" decision procedure, such a decision procedure is not a desirable aim for moral theory in any case, for the reason that it leaves out something important about the making of moral decisions (2004). As Annas's argument reveals, there are undesirable consequences arising from the expectation that we seek out concrete action guidance, and avoid vague, unspecific advice at all costs. By doing so, we lose an important sense in which the moral decisions we make are our own. Further, by maintaining an emphasis on agents as well as acts, and by rejecting the assumption that a moral theory should provide a single action guiding principle, virtue ethics enables us to account for action guidance and moral development in a way that avoids the problems identified.

\subsection{Can Environmental Virtue Ethics Provide Concrete Action Guidance?}

\subsubsection{One Possible Solution: Environmental Vices and 'Obvious' Prohibitions}

In any case, it is worth turning our focus to the concerns around whether virtueoriented approaches to environmental ethics will leave us with a limited range of action guidance in the relevant cases. As I mentioned in chapter two, Hursthouse recognizes the objection that an environmental virtue ethics, regardless of whether it makes use of existing virtues and vices, or seeks to introduce "new" virtues, will fail to provide more than a list of obvious prohibitions, but maintains that rival theories are equally as problematic (2007: p.167). 
She does not, for instance, deny that other environmental ethicists like Paul Taylor provide useful principles of how we should go about weighing up the competing claims between human beings and other life forms, or on how to minimize our harms to the ozone layer. The claim is rather that such principles yield fairly obvious prohibitions, which even the most minimally committed environmentalists already live in accordance with, something that falls short of providing guidance on what detailed changes are required in how we interact with the environment (Hursthouse, 2007: p.168).

Hursthouse's explanation for why environmental virtue ethics fails to provide such detailed changes is as follows: virtue ethicists typically answer questions like "What should I do?” or "How should I live?” by reference to how someone who actually possessed the virtues to a high degree would act or live. Given that we have so few exemplars of the relevant virtues, if any at all, it comes as little surprise that we are limited in terms of what we know regarding the characteristic behaviour of a person who possesses environmental virtue to a high degree (2007: p.168).

Despite Hursthouse's explanation, I claimed that an absence or shortage of environmental exemplars presents an epistemological challenge to environmental virtue ethics, similar to the challenge facing her theory in non-environmental ethical terms. One might argue, that the theory once again fails to tell non-virtuous agents "what to do", and that it also fails to tell us how to figure out what to do, to the extent that environmental virtue ethicists are ruled out from responding that those of us who are not environmentally virtuous can seek out the guidance of someone who is. To alleviate this concern, I argued that Hursthouse can claim that the theory still provides action guidance, without putting itself in a threatening position theoretically, consistent with her remarks regarding eudaimonia. Even though the theory is concerned with our living well, she thinks, virtue ethics is not committed, in advance, to our living well being a realizable state of affairs. Our past and present ecological folly might have put it beyond our grasp, she thinks (Hursthouse, 2007: p.169). It is simply a possibility that environmental virtue, and by extension, the acts from environmental virtue (in the sense of being actions that a fully virtuous agent would perform) are just not available to us.

Nonetheless, parallel with the arguments made earlier in this chapter, virtue ethics does not commit itself to a single action-guiding principle, or provide a decision procedure available to anyone with the right skills. Virtue ethicists reject this view as 
problematic, for the reasons outlined by Annas. By not committing itself to a single action-guiding principle, we can see that the theory nonetheless provides action guidance in another way, namely through the use of v-rules. As I argued in the previous chapter, vice-rules are action guiding in the sense that they enable nonvirtuous agents to identify the actions they ought not to do. At very least then, I maintain that Hursthouse is not mistaken in thinking that her theory generates a list of prohibitions, and that it is action guiding in this very way. Each vice generates a prohibition - do not do what is greedy, intemperate etc.

\subsubsection{Objections to All Virtue Oriented Approaches to Environmental Ethics}

However, it is unlikely that environmental ethicists would be willing to accept a list of supposedly obvious prohibitions as the final word on how we ought to act with regard to the environment. It is appropriate at this point to again consider questions around what is required of an adequate environmental ethic, as far as action guidance is concerned. According to Sandler, an environmental ethic is adequate to the extent that it:

A: Provides a basis for reliable, sustained, and justified critique of environmentally unsustainable practices, policies and lifestyles.

B: Provides action and policy guidance in concrete situations involving individual or community interactions or relationships with the natural environment.

C: Provides arguments, reasons, or justifications that are efficacious in moving people to perform the actions or adopt the policies that are recommended (2007: p.108).

One of my aims for this chapter is to show that critics of Aristotelian virtue ethics are not warranted in rejecting the theory as one that fails to provide action guidance. For this reason, my focus is solely on condition $\mathrm{B}$, and in particular, on the question of whether such a theory is ruled out from being able to provide action guidance in concrete situations from the beginning.

In relation to condition $\mathrm{B}$, it is worth outlining what Sandler takes to be a major obstacle for any virtue-oriented approach to environmental ethics on this front (i.e. obstacles for Aristotelian and non-Aristotelian approaches alike). One specific objection a critic might raise, according to Sandler, is the claim that a "virtue- 
oriented approach cannot provide sufficient guidance on concrete environmental problems and issues" (Sandler, 2007: p.108). Specifications of environmental virtues might provide descriptions of the sorts of dispositions a person ought to cultivate in regard to the natural environment and give an indication of the general environmental behaviours a person ought to engage in, he continues. It may nonetheless be objected that "they do not provide specific action guidance in particular situations or a decision-making mechanism for people who are not already environmentally virtuous to determine what actions they should perform and what policies they should support" (Sandler, 2007: p.111).

\subsubsection{Should Environmental Virtue Ethics provide a Decision Procedure?}

On the basis of the arguments made earlier in this chapter, let us consider how a proponent of Aristotelian virtue ethics might respond to the problems outlined by Sandler above. The first thing to note is that the objection is remarkably similar to the concerns raised by Louden, pertaining to whether or not virtue ethics is ruled out from providing concrete action guidance to non-virtuous agents, as a result of its inability to provide a "one-size-fits-all” decision procedure. In this way then, following Annas, one could respond by undermining the assumption that we should want a moral theory, (as a theory of environmental ethics or otherwise), that seeks to provide a single action-guiding principle, capable of providing action guidance in all moral quandaries, to any agent with the necessary technical skills. There are undesirable consequences of this sort of approach, according to Annas, which arise from the expectation that we seek out concrete action guidance, and avoid vague, unspecific advice at all costs. We lose an important sense in which the ethical decisions we make are our own.

Perhaps, in relation to environmental ethics, the costs of such a line of thinking are even higher. Assuming there is a decision procedure for environmental decision making, and I make a wrong moral decision with regard to the environment, there is a worry that the theory will lose a sense in which I am blameworthy for my action, for example, if I put my wrong decision down to my getting the theory wrong, or the theory being wrong. It might be argued then that a theory which seeks to provide concrete, specific action guidance at all costs, whether as a theory of interpersonal ethics, or a theory of environmental ethics, will run into serious problems of its own, 
akin to those mentioned previously.

\subsubsection{Hursthouse and Concrete Action Guidance: Some Prospects}

In case it is argued by a critic that this response fails to appreciate the unique importance of action guidance to theories of environmental ethics, there is another possible strategy for Aristotelian virtue ethicists wanting to respond to the concern outlined here. One could consider how Sandler meets the objection at hand then determine whether there is anything inconsistent with what Sandler's response consists in, and what an amended Aristotelian account consists in. In the remainder of this chapter I will argue that there are no significant inconsistencies between the two, aside from the difference in which a principle of right action is employed. I will re-visit the arguments made in chapter three, to show that the qualified agent view is not implausible as a theory of action assessment, and show further, that the results it generates are not inconsistent with those generated by Sandler's account. If I am right about this, it follows that Hursthouse is not ruled out from formulating her arguments in a way that resembles Sandler's which, crucially, leaves open the possibility that her theory can provide guidance around which policies to support, in the way that Sandler's does.

Sandler argues that his theory can provide specific guidance on which actions to perform and which policies to support, if we are to take on an alternative account of right action. Specific action guidance can be accomplished through an agent-relative target principle of right action, Sandler argues, setting out the principle as follows:

An action is right to the extent that it better hits the target of the operative virtues than the other courses of action available to a particular agent under the circumstances (2007: p.102)

The advantages of this principle, according to Sandler, lie in the fact that it is sensitive to certain agent-particularities, namely their abilities, limitations and character weaknesses of such agents, in a way that (he thinks) qualified agent, and ideal observer principles fail to (2007: p. 93).

The principle supports a virtue-oriented method of decision making, where specific action guidance is achieved through the application of the operative virtues or v-rules to a situation, "appropriately informed by moral wisdom and assisted by the counsel of mentors, the study of models, and collaborations with others" (Sandler, 2007: p.102). For Sandler, a v-rule corresponds to a substantive specification of a 
particular virtue. One such example is compassion, which includes a disposition to help alleviate the suffering of other people when there is little cost to oneself. From this, one can generate the v-rule: "help alleviate the suffering of others when there is little cost to oneself' (Sandler, 2007: p.98). Another example Sandler raises is the disposition to avoid compromising the availability of basic environmental goods, a nameless virtue, but one he considers to be a virtue of sustainability. From this disposition, one can generate the v-rule: "do not compromise the availability of basic environmental goods" (Sandler, 2007: p.98). The important feature of v-rules, for Sandler, is that they "can be taught, learned and applied in concrete situations by those who do not have the corresponding (i.e. virtuous) dispositions", and that they can be derived through reflection (individual or collaborative reflection) (Sandler, 2007: p.98).

The way in which Sandler goes about meeting the first specific objection raised earlier then, is as follows. In response to the claim that virtue oriented approaches fail to provide sufficient guidance on concrete environmental problems and issues, Sandler concedes that his theory does not provide a finite set of rules or principles that can be applied by anyone in any situation. In this way, the theory does not yield a unique action guiding prescription, and is instead pluralistic and uncodifiable. The theory does, however, provide a principle of right action as described above, and is well endowed with action-guiding resources, including v-rules, role models, and collaborative discourse. That the theory leaves room for such resources is advantageous, in the sense that they can help a person come to identify the courses of action which (in line with his account of right action) hit well the targets of the operative virtues in the situation (Sandler, 2007: p.111).

Armed with the normative resources to provide action guidance in both environmental and non-environmentally related contexts, Sandler applies his approach to the issue of genetically modified crops. The position that his approach yields is one of selective endorsement regarding genetically modified crops. Specifically, he argues that the approach justifies a general presumption against the use of such technologies, when the use of such technologies is the primary strategy for meeting agricultural challenges. In some circumstances, however, particular genetically modified crops ought to be supported, according to Sandler, as part of an integrated approach which addresses the social, economic, political, and ecological dimensions of those challenges (2007: p.111, 123). 
The justification behind Sandler's first claim seems to be this: There is a propensity among politicians and industry leaders to rely on genetically modified crops as the technological fix to our agricultural challenges, which represents the expression of a disposition to meet our material needs primarily by domination and control, and a failure to hit well the target of humility, the operative environmental virtue in this case (Sandler, 2007: p.135). The justification behind Sandler's second claim seems to be that, on account of the fact that genetically modified crops are not inherently bad, the use of such technologies is permissible if they hit well the target of sustainability and environmental stewardship, in meeting the relevant agricultural challenges (Sandler, 2007: p.127).

The conclusion Sandler reaches in advocating this approach is that, by reflecting on which virtues are operative in the case of genetically modified crops, along with an explanation about what would constitute hitting the target of those operative virtues, the theory provides concrete action guidance in this way. Importantly, while the approach provides resources for working through difficult cases, it does not eliminate the need for good judgement and discernment, which, rather than being a shortcoming of the approach, remains an ineliminable feature of ethical decision making, according to Sandler (2007: p.140).

At this point then, let us consider Sandler's virtue oriented approach to environmental decision making in relation to Hursthouse's environmental virtue ethics, and establish whether it is any more advantageous at all. The first thing to note is that nothing in the above discussion prevents Hursthouse from utilizing vrules in the way described. Granted, there are disagreements between the two theories as to what gives virtues (and thereby v-rules) their normative force. Sandler, for example, argues in favour of a pluralistic, teleological, naturalistic account of what makes a character trait a virtue, whereas Hursthouse argues that a character trait is a virtue that is needed by a human being for eudaimonia, to flourish or live well (Sandler, 2007: p.28; Hursthouse, 1999: p.28). Structurally, however, this difference has no stake in how v-rules are understood, so Hursthouse's argument cannot be ruled out from making use of v-rules in the way that Sandler does, as a valuable action guiding resource for agents who are not already environmentally virtuous. A further similarity in both theories is the absence of a decision-making mechanism available to anybody who possesses the right technical skills, as a means of discerning what one ought to do. 
One obvious difference between Sandler's virtue-oriented approach to environmental decision making and Hursthouse's environmental virtue ethics is that they endorse different principles of right action. A critic might respond here by arguing that this difference rules out Hursthouse's account from meeting the objections made earlier, in the way that Sandler's account does, particularly if Hursthouse's account is shown to be implausible.

Indeed, Sandler explicitly argues that the qualified agent principle is implausible, on account of the fact that it fails to account for actions that seem appropriate for nonvirtuous agents even though no virtuous agent would perform them, and similarly, that it fails to account for actions that are inappropriate for non-virtuous agents, even though they are appropriate for virtuous agents (2007: p.88-89). Further, he thinks that the principle fails to account for cases in which contextual factors lead a virtuous person to do what is intuitively wrong, even when they are acting in character, and further, that it fails to account for agent-particularities, including her abilities, commitments and so forth.

In response then, let us contextualize the arguments made in the previous chapter in relation to this charge. The first two objections listed above draw their inspiration from Robert Johnson, who argues that the qualified agent principle generates the wrong result for non-virtuous agents when faced with certain scenarios, in which the course of action appropriate to them is not the characteristic behaviour of a completely virtuous agent (2003). I argued that the cases described by Johnson, once deconstructed, are similar in form to a familiar case identified by Hursthouse the case of the two timing lover - in which action assessment and action guidance come apart. In cases of this kind the theory does not generate the wrong result, I argued, on account of the fact that the morally right action is simply beyond the capacity of the non-virtuous agent in question. Following van Zyl, however, I showed that the theory nonetheless provides action guidance to the non-virtuous agent, namely by the prohibition generated by the relevant vice-rule in question.

The same argument can be applied to the first two objections identified by Sandler here: in both cases, the qualified agent principle does not fail - it is simply the case that the morally right action is not available to the non-virtuous agent in question. The non-virtuous agent still has an idea of what to do in such cases, however, they ought to avoid doing what is dishonest, cruel, unjust and so forth.

In the previous chapter, I argued that (aside from irresolvable and tragic dilemmas), 
there are, by hypothesis, no such cases in which a virtuous agent performs the intuitively wrong action while acting in character, as Sandler seems to suggest is both a possibility, and a shortcoming for the qualified agent principle. The principle itself holds that "An action is right iff it is what a virtuous agent would characteristically (i.e. acting in character) do in the circumstances" (Hursthouse, 1999: p.28), so, if correct, actions we would want to categorize as intuitively wrong actions resulting from character limitations or factors external to the agent (such as sleep-deprivation) could be assessed as actions that are not the characteristic behaviour of a virtuous person. In order to defend my first claim though, I also argued that the principle successfully embodies the "characteristically" clause, without compromising its distinctively virtue ethical explanation about what makes an action right.

In regard to other limitations identified by Sandler, such as one's capacity to walk or one's personality type, I argued that such factors have no stake in whether or not a person can be virtuous, nor that there was any inconsistency in one v-rule providing different courses of action, based on the abilities of the agent in question, along with the extent to which that agent possesses the practical wisdom necessary to apply the virtue in question, in the best way possible.

If my arguments here are sound, then Hursthouse's environmental virtue ethics survives the objections on this score, and is therefore in a neutral position to Sandler's virtue oriented approach, when we consider the question of whether it is ruled out from being able to provide concrete action guidance and meet the action guidance objection raised earlier.

One final question remains then: does Hursthouse's theory leave room to provide concrete action guidance in same way as Sandler's virtue oriented approach? In regard to Sandler's virtue oriented assessment of genetically modified crops, it is unclear whether there is anything distinctively non-Aristotelian about the way in which he has gone about justifying his claims regarding how we ought to assess the policies, actions and attitudes in question. By arguing that the attitudes of politicians and industry leaders reflect dispositions of manipulation and control with regard to certain technologies, and fail to hit well the target of humility, Sandler has indeed formulated this claim in terms of his target centred principle of right action, but there is no clear reason to think that Hursthouse could not formulate the same normative claim in terms of her qualified agent principle, so long as she takes 
humility to be an environmental virtue.

And further, despite the fact that her theory does not talk about the virtues of sustainability, and environmental stewardship, there is nothing that prevents Hursthouse from making normative claims akin to Sandler's second claim, in terms of the qualified agent principle. In this way then, Hursthouse is not ruled out from formulating her arguments in a way that resembles Sandler's. Crucially, this leaves open the possibility that her theory can provide guidance around which policies to support, in the way that Sandler's does.

\subsection{Conclusion}

In this chapter, I set out to show that critics of Aristotelian virtue ethics are not warranted in rejecting the theory as one that fails to provide action guidance. I argued, following Annas, that there are compelling reasons to undermine the idea that we ought to seek out a decision procedure model for ethical theory, in both interpersonal ethics, and environmental ethics, on account of the fact that such a procedure removes an important sense in which the agent performing the act is either praiseworthy or blameworthy.

However, in case such an objection is not satisfactory for critics who think that environmental ethics should be concerned with providing concrete action guidance at all costs, I offered a further response. If my analysis is correct, the possibility is left open for Hursthouse's theory to meet the action guidance adequacy condition for environmental ethics in the same way as Sandler's theory, by identifying the ways in which it is not inconsistent with Sandler's virtue oriented approach to environmental decision making. The only significant difference, I have argued, is that Hursthouse's theory provides a different account of right action, one that is defensible for the reasons given in chapter three. 


\section{Conclusion}

In this thesis I set out to show that virtue oriented approaches to environmental ethics are in a position to provide satisfying answers to both central ethical questions, namely, "What kind of person should I be?” and "What should I do?” with regard to the natural environment. In chapter one, I argued that two virtue-oriented approaches - Rosalind Hursthouse's environmental virtue ethics and Philip Cafaro's account of environmental vice - provided insights into the causes and solutions surrounding the environmental crisis, particularly in terms of relevant character traits and attitudes. Following the suggestion that an account of the norms of character that ought to govern our relationship with the natural environment requires a background theory of virtue, I outlined Hursthouse's eudaimonistic account of what makes a character trait a virtue, defending it against a few criticisms from Ronald Sandler and concluding that he is mistaken in asserting that we need to move to a more inclusive, pluralistic account.

In chapter two, I outlined Hursthouse's theory of right action, and considered an epistemological objection to this account. The objection is that an imperfect agent cannot know what a fully virtuous agent would do in certain circumstances because they do not possess the virtues. Hursthouse responds to this objection, stating that the obvious thing for an imperfect agent to do in these circumstances is to find a virtuous agent, and ask them what they would do, should this be possible (1999: p.35). She also claims that we come to know how to act with regard to the environment by conceiving of how someone who possesses the virtues would act, but also that we have very few exemplars of the relevant virtues (2007: p.168). I interpreted this latter claim as a concession, albeit an unintentional one, that her environmental virtue ethics cannot provide action guidance. I argued that this problem can be alleviated, but not by showing that imperfect agents can seek out the guidance of environmentally virtuous agents. Instead I argued that the theory provides action guidance in the form of v-rules, where each vice generates a corresponding prohibition.

As I suggested in the introduction, the spheres of interpersonal ethics and environmental ethics are not entirely divorced from one another, and in this way, problems facing virtue ethics in this first area have direct implications for the theory on the latter. In this way, chapter three was concerned with a different family of 
objections against Hursthouse's principle of right action. These pertain to nonvirtuous agents, where the worry is that her principle of right action fails to generate the right result for such agents, in cases where the intuitively right action is not the characteristic behaviour of a virtuous person. I responded by showing that the cases which critics of virtue ethics are concerned with here are similar to a case which Hursthouse's distinction between action guidance and action assessment is able to account for. I then tried to account for them in a similar fashion.

In chapter four I considered the worry that virtue oriented approaches to environmental ethics will fail to provide concrete action guidance in specific environmental contexts. Following Julia Annas, I argued that there are compelling reasons to think that the goal of constructing a theory that provides concrete action guidance to any agent in any situation will likely run into serious problems of its own, in that it looks to remove an important sense in which the agent performing the act is either praiseworthy or blameworthy. Independent of this response, I argued that Hursthouse's theory is able to provide the sort of action guidance that the critics are interested in, by showing that her theory is consistent, in the relevant respects, with a theory that provides a virtue-oriented approach to environmental decision making, namely Ronald Sandler's. 


\section{Bibliography:}

Annas, Julia. "Being Virtuous and Doing the Right Thing" in Proceedings and Addresses of the American Philisophical Association, Vol. 78, No.2, 2004: p. 61-75

Cafaro, Philip. "Gluttony, Arrogance, Greed and Apathy: An Exploration of Environmental Vice" in Environmental Virtue Ethics. Ed. Philip Cafaro \& Ronald Sandler. Oxford: Rowman \& Littlefield Publishers, 2005

Das, Ramon. "Virtue Ethics and Right Action: A Critique" in Routledge Companion to Virtue Ethics. Ed. Lorraine Besser-Jones \& Michael Slote. London: Taylor \& Francis Ltd, Forthcoming

Foot, Philippa. Natural Goodness, Oxford: Oxford University Press, 2001

Frasz, Geoffrey. "Environmental Virtue Ethics" in Environmental Ethics, 15, 1993: p.260-274

Heyd, David. "Beyond the Call of Duty in Kant's Ethics" in Kant-Studien, 71, 1980: p.308-324

Hursthouse, Rosalind. On Virtue Etthics, Oxford: Oxford University Press, 1999 --- "Environmental Virtue Ethics" in Working Virtue: Virtue Ethics and Contemporary Moral Problems. Ed: Rebecca L. Walker \& Philip J. Ivanhoe. 2007: p.155-171

--- "Virtue Theory and Abortion" in Philosophy and Public Affairs, 1991: p.223-246

Louden, Robert. "On Some Vices of Virtue Ethics" in American Philosophical Quarterly, Vol. 21, No.3, 1984: p.227-236

Johnson, Robert. "Virtue and Right" in Ethics, 113, 2003: p.810-834

Park, Chris. Dictionary of Environment and Consevation. 2007. New York: Oxford University Press 
Sandler, Ronald. "Introduction" in Environmental Virtue Ethics, Ed. Philip Cafaro \& Ronald Sandler. Oxford: Rowman \& Littlefield Publishers, 2005

--- Character and Environment, New York: Columbia University Press, 2007

Svensson, Frans. "Virtue Ethics and the Search for Right Action" in Ethical Theory and Moral Practice, 13 2010: 255-271

van Zyl, Liezl. "Right Action and the Non-Virtuous Agent" in Journal of Applied Philosophy, Vol. 28, No.1, 2011: p.80-92

Zagzebski, Linda Trinkaus. Divine Motivation Theory, Cambridge: Cambridge University Press, 2004.

--- "Exemplarist Virtue Theory" in Metaphilosophy, Vol. 41, Issue 1-2, 2010: p.41-57 